Fares ZOUAOUI 1,2, Saliha BOUROUINA-BACHA ${ }^{2}$, Mustapha BOUROUINA ${ }^{2}$, Nicole JAFFREZIC-RENAULT ${ }^{*}$, Nadia ZINE${ }^{1}$, Abdelhamid ERRACHID ${ }^{1, *}$

${ }^{1}$ University of Lyon, Institute of Analytical Sciences, UMR 5280, CNRS, 69100 Villeurbanne, France.

${ }^{2}$ University of Bejaia, Laboratory of Environmental Engineering, Bejaia, Algeria.

Corresponding authors' email address: Nicole JAFFREZIC-RENAULT nicole.jaffrezic@univ-lyon1.fr Abdelhamid ERRACHID abdelhamid.errachid-el-salhi@univ-lyon1.fr

\begin{abstract}
Despite the enormous development of instruments for analyzing a wide variety of compounds, applied in different fields such as health, environment or quality control, the demand for increasingly sensitive and selective techniques continues to grow. In this regard, efforts have been made to highlight more appropriate techniques. Electrochemical sensors based on molecularly imprinted polymers (MIPs) offer an interesting alternative since they allow reaching high sensitivity and selectivity and they are inexpensive and easily adaptable to miniaturization. The choice of the functional monomer in the synthesis of MIPs is based on its capacity to provide complementary interactions with the target molecules. The various excellent properties of chitosan, as a biosourced polymer, make it a promising alternative to conventional functional monomers. This review reports on the principle of the MIPs technique describing the different possible approaches in their synthesis. It aims to provide an overview of the value of using chitosan as a functional monomer by highlighting its applications in electrochemical sensors.
\end{abstract}

Keywords: Molecularly imprinted polymers, Chitosan, Electrochemical sensors, Electrodepostion, Coating.

\title{
Introduction
}

Conventional analytical techniques (chromatography, Nuclear Magnetic Resonance (NMR), mass spectrometry (MS), etc.) used for monitoring in different fields such as medicine, clinical biology, the food industry and the quality control of our environment (monitoring industrial or domestic discharges) are generally complex, expensive, bulky and often difficult and time-consuming to implement, and they require highly qualified personnel. In addition, conventional procedures consist in taking samples from the monitored environments and analyzing them in the laboratory. The steps of sample preparation, incubation, and processing of results often greatly increase the total analysis time [1]. In order to carry out these analyses, there is a need to set up rapid, simple, inexpensive, selective techniques and to design compact monitoring tools operating on site, in real time.

Among the devices capable of responding to this demand, sensors present the essential function of detection or even quantification of a physical, biological or even of a chemical phenomenon in a measurable signal and directly usable by humans. Electrochemical sensors are a promising choice because of their simplicity, sensitivity, ease of implementation and generally low measurement costs, but also for their varied applications in the field of health, of the environment or of quality control of food products. Electrochemical sensors are based on different electrochemical techniques: potentiometry, voltammetry, amperometry, impedimetry [2].

Biological elements (antibodies, enzymes, microorganisms, DNA, etc.) are generally used for recognition in order to increase sensitivity and specificity, which are generally lacking in chemical sensors. However, as they are biomolecules, their use is limited to mild conditions of $\mathrm{pH}$, temperature and nature of the medium in order to avoid denaturating the protein. In addition, using these biological elements is not so simple. Sourcing them and immobilizing them on the electrode surface require considerable skill $[3,4]$.

Due to the need to overcome these limitations, an alternative has been developed which consists of using molecularly imprinted polymers (MIPs). MIPs have been used as an artificial recognition material whose binding site size and shape are complementary to the template molecules for their specific recognition. This approach was established in 1972 by Wulff and Sarhan [5]. To generate MIPs with selective cavities, a monomer is simply polymerized in the presence of the target molecule and a crosslinking agent leading to the formation of a highly cross-linked functional monomer/template complex. The formation of the complex has been theoretically studied in several articles [6,7]. Cavities specific to the target molecule are then obtained after extracting the template from the polymer. Template/monomer and crosslinking agent/monomer ratios play an important role in the synthesis of MIPs improving the efficiency $[8,9]$. MIPs are characterized by very interesting properties such as physical resistance, robustness, resistance to high pressures and temperatures and high inertia towards various chemicals [10], and are produced at low cost. In addition, MIPs have a high affinity and selectivity towards target molecules; they are comparable to natural receptors [11]. MIPs are widely used in various fields, such as liquid chromatography, capillary electrochromatography, solid phase extraction, therapy, preparation of artificial antibodies and enzymes, catalysts and syntheses, sensors, etc. [12,13]. interactions with the matrix molecules [14]. Chitosan (CS) is a natural polysaccharide obtained by deacetylation of chitin which is the 
most abundant non-toxic, biodegradable and biocompatible natural amino polysaccharide [15]. Chitosan has three types of reactive functional groups, one amine group and two primary and secondary hydroxyl groups. This structure thus allows numerous chemical modifications, and can support a succession of chemical reactions such as the reaction with aldehydes and acetones, grafting, $\mathrm{H}$ bond with polar atoms, crosslinking, etc. The functional properties of chitosan films can be improved when combined with other materials [16]. Due to the positive charges on its amine groups, the cationic biopolymer can interact with anionic molecules. These unique properties make CS suitable for a wide range of applications in the food, cosmetic and pharmaceutical, sensor and biosensor fields $[17,18]$. The presence of reactive functional groups on the polysaccharide chain of CS gives it flexibility, excellent film-forming capacity, good adhesion, biocompatibility, high mechanical resistance, the possibility of undergoing structural modifications, which makes it suitable for preparing MIPs and building electrochemical sensors [19,20]. It is well known that the behavior of chitosan can be affected by several parameters such as $\mathrm{pH}$ and humidity [21,22]. Treatment of chitosan with crosslinking agents or by chemical modification are common strategies to improve its physico-chemical characteristics [23]. Chitosan has been used to make membranes, thin films and three-dimensional structures. These forms are obtained by different methods such as electrodeposition [24] and drop-coating [25]. Electrodeposition is very convenient because it is a simple, fast and low-cost technique, but also it makes it possible to obtain controlled films [26].

This review describes the principle of MIPs and the approaches used to synthesize them emphasizing the different criteria for choosing the reagents and the limitations of this technique. In addition, it accounts for the advantage of using chitosan as a functional monomer by highlighting its applications in electrochemical sensors.

\section{Natural origin of chitosan}

\section{l.1. Structure and sources of Chitin}

Chitin, first identified in 1884, is the second most abundant biopolymer in nature after cellulose. Its chemical structure consists of $\mathrm{N}$ acetylglucosamine units. Chitin's physical structure includes three allomorphs, due to the arrangement of macromolecular chains, $\alpha$, $\beta$ and $\gamma$-chitin (figure 1). $\alpha$-chitin is one of the most abundant allomorphs in which polymer chains are arranged in the same direction and parallel. $\beta$-chitin is less frequent in nature and presents anti-parallel chains. The $y$-chitin, according to the studies, is a variant of the $\alpha$ or $\beta$ - family [27].

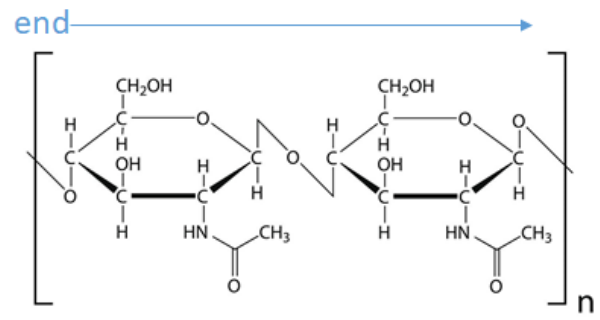

.

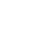

Chitin is present in co-products in the form of chitin-proteins-calcium carbonate complexes [15]. Chitin can be obtained from various sources (Table 1), it is mainly found in exoskeletons, mollusks and various microorganisms $[15,28]$.

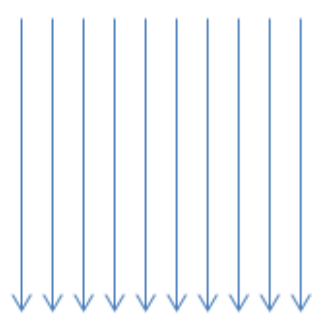

$\alpha$-chitin

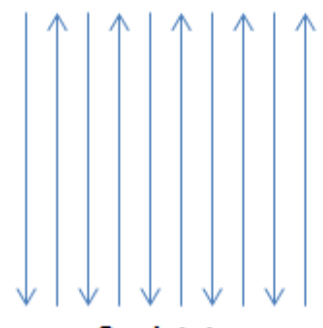

$\beta$-chitin

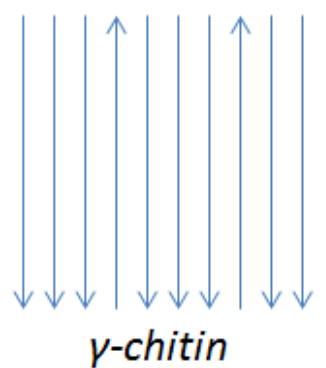

Figure 1: Allomorph types of chitin. 
Table 1: Main sources of chitin.

\begin{tabular}{ll}
\hline a-chitin & $\beta$-chitin \\
& \\
\hline $\begin{array}{l}\text { Fungi, yeast cell walls, krill, lobster, crab, tendons, } \\
\text { shrimp shells, insect cuticle. }\end{array}$ & $\begin{array}{l}\text { Squid pens, tube synthesized by pogonophoran and } \\
\text { vestimentifera worms, lorica built by some seaweeds }\end{array}$
\end{tabular}

\subsection{Extraction of chitin}

Usually, two types of extraction process are used to obtain pure chitin: chemical and biological methods (Fig.2). Chemical extraction is based on three stages; between these different stages, washing operations are necessary [27].

Demineralization: by hydrochloric acid to eliminate minerals. This consists in the elimination of the calcium carbonate and calcium chloride.

$>$ Deproteinization: by sodium hydroxide to eliminate proteins.

Bleaching: by sodium hypochlorite to remove pigments.

Biological treatments offer an alternative way to extract chitin, to avoid acidic and alkaline treatments. Lactic acid-producing bacteria and proteases from bacteria have been used for the demineralization and deproteinization steps respectively [29]. Chitin is highly hydrophobic and insoluble in water and most organic solvents are due to the presence of acetyl groups [15], so it can be used in more applications when transformed into chitosan.

\section{I.3. Deacetylation of chitin}

The deacetylation step consists in converting chitin to chitosan by the removal of acetyl groups and leads to partial deacetylation. The border between chitin and chitosan corresponds to a degree of deacetylation (DD). This makes the degree of deacetylation an important property in the production of chitosan since it determines the free amino groups in the polysaccharides. Indeed, it affects the physicochemical properties and thus determines its appropriate applications. DD is an important criterion for distinguishing between chitin and chitosan, defined as the fraction of glucosamine $/ \mathrm{N}$-acetyl glucosamine: note that:

$>$ for a $\mathrm{DD}<60 \%$, the polymer is named chitin.

$>$ for a DD> 60\%, the polymer is named chitosan [30].

The degree of acetylation controls the proportion of amine and acetyl groups in the carbonic chain and is directly related to the solubility and acid-base behavior of the polymer [31]. Many methods have been developed to determine DD, such as the conductimetric assay [32,33], potentiometric titration [34], UV spectroscopy, IR spectroscopy, ${ }^{1} \mathrm{H}$ NMR spectroscopy, HPLC analysis [35], etc. Deacetylation can occur either chemically or enzymatically.

\section{- Chemical deacetylation}

Sodium or potassium hydroxides are usually used at high temperature [27]. The alkaline treatment can be repeated to achieve complete deacetylation [36]. It has been reported that the DD can be affected by temperature, processing time and alkali concentration. Chemical deacetylation is used more commonly because of its low cost; however, the negative points are high energy cost, waste of concentrated alkaline solution which leads to an increase in environmental pollution, the fact that it is not easily controlled and lead to a broad and heterogeneous range of products [37].

\section{- Enzymatic deacetylation}

Chitin deacetylase for the preparation of chitosan polymers is used. It partially catalyses the hydrolysis of $\mathrm{N}$-acetamido bonds in chitin to produce chitosan $[37,38]$. Enzymatic deacetylation is a sustainable process and offers the possibility of controlling and predicting the bioactivities of chitosan. Therefore, the resulting chitosan has a more regular deacetylation pattern than a chitosan treated with hot alkali $[39,40]$. 


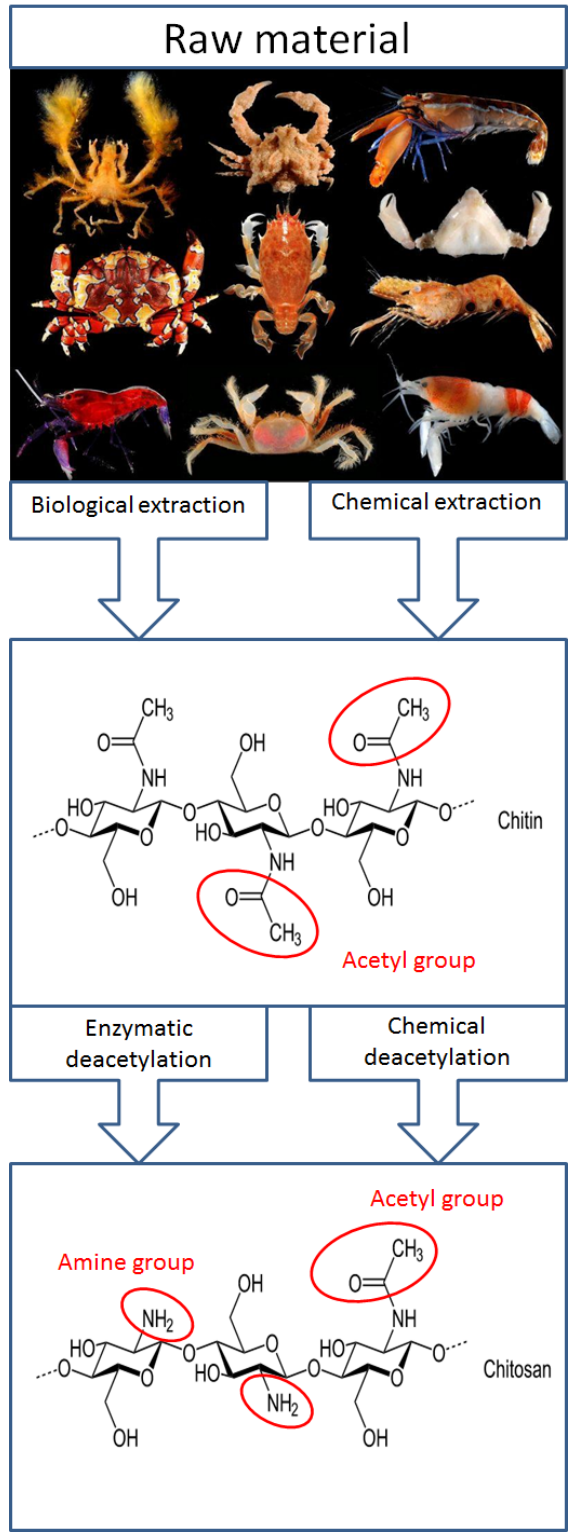

Figure 2: Preparation of chitin and chitosan from raw material

\section{Properties of chitosan}

\section{II.1. Structure}

Chitosan (CS) is the name given to chitin after the deacetylation process (Figure 2). CS is an amino sugar with a molar mass of 179 $\mathrm{g} / \mathrm{mol}$ glucosamine. It is a family of linear polysaccharides with a molar fraction DD of D-glucosamine and a fraction (1-DD) of $N$ acetylglucosamine [28]. Chitosan is thus considered as a copolymer with three types of reactive functional groups, a primary amino group, and one primary and two secondary hydroxyl groups (one primary amine group (C2) and two hydroxyl groups (C3, C6) perrepeat unit) (figure 3) 


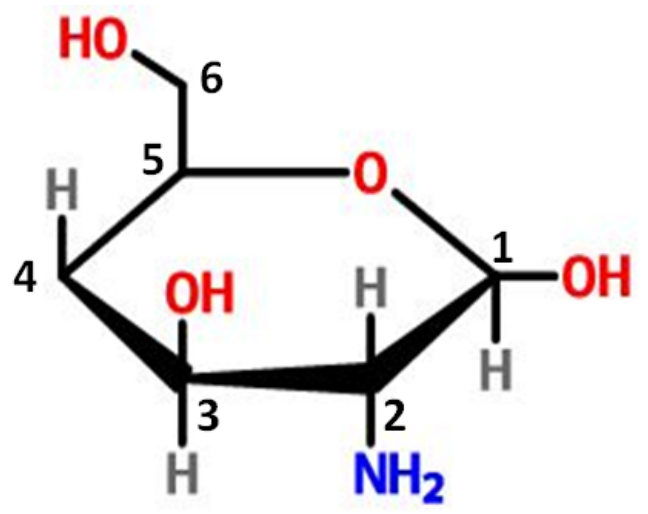

Chitosan is considered as a strongly basic polysaccharide. This polymer has multiple physical and chemical properties that make it a credible candidate for many applications including foods [41], pharmaceutical and biomedical [42], cosmetics, textile and agricultural [43], treatment of water and wastewater [44], etc.

Figure 3: Structure of D-glucosamine

\section{II.2. Molecular weight $\left(\mathrm{M}_{\mathrm{w}}\right)$, Viscosity and crystallinity of chitosan}

Molecular weight $\left(\mathrm{M}_{\mathrm{w}}\right)$ is one of the most fundamental parameters in the characterization of a polymer. Chitosan is a high molecular weight biopolymer. For a commercial product $\mathrm{Mw}$ is 100 to 1200 kilodaltons $(\mathrm{kDa})$; the latter varies according to the sources of raw materials and the method of preparation. The molecular weight of chitosan is an important characteristic influencing the rheological properties of the solutions and therefore their conditions of implementation. High molecular weight CS usually gives very viscous solutions. The determination of $\mathrm{Mw}$ can be done by light scattering measurements and viscometry $[45,46]$ or by steric exclusion chromatography [47].

Viscosity is one of the most important characteristics of chitosan. The viscosity depends on the $\mathrm{DD}, \mathrm{Mw}$ and also on the $\mathrm{pH}$ value because these parameters determine the charge density on the polymer chain. The structure of the macromolecules is very extensive when the charge density is high due to the charge repulsion phenomenon, so viscosity is then hight. On the other hand, when the polymer is poorly ionized, the macromolecular chains are in the form of statistical balls characterized by low viscosity. As with other polysaccharides, viscosity drops when the temperature increases [48].

Crystallinity is also an important parameter because it allows the control of a certain number of properties such as the accessibility of internal sites in the macromolecular chains, the swelling properties in water or even the diffusional properties. Chitosan is generally a semi-crystalline material. The crystallinity is usually determined by X-ray diffraction or by NMR [15].

\section{II.3. Properties of chitosan}

Chitosan is a strongly basic polysaccharide, with a cationic character in an acid medium. It is anyway the only water-soluble cationic polyelectrolyte of natural origin [48]. CS is a hydrophilic biopolymer and a very polar molecule; this property is due to the presence of numerous hydroxyl and amine groups at the level of the glucosamine units.

It is interesting to note that chitosan is a polycationic polymer having one $\mathrm{NH}_{2}$ group and two $\mathrm{OH}$ groups on each glucosamine. These three groups are very reactive and are very important with respect to the properties of the polymer. The strong functionality of chitosan gives it a considerable opportunity for chemical modification [49]. The amino groups form a specific binding platform with other groups external to the polymer, which is an important biofabrication feature [50]. They may cause chemical reactions such as alkylation, quaternization, reacting with aldehydes and ketones, grafting, etc [29].

On the other hand, hydroxyl groups give some flexibility to the material and are also responsible for modifying its biological and physical properties [50]. The hydroxyl functionality also leads to some reactions like o-acetylation, $\mathrm{H}$-bonding with polar atoms, crosslinking, grafting, etc. [29].

In contrast to chitin, the presence of free amine groups along the chitosan chain allows this macromolecule to dissolve in diluted

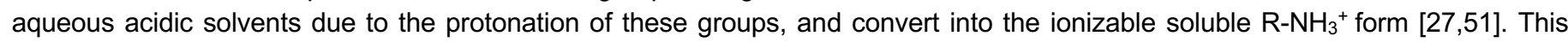
exceptional peculiarity of being positively charged, allows chitosan to react with negatively charged compounds and to fix them solidly by ionic bonds, and gives it very numerous properties, such as strong electrostatic interaction, the possibility of hydrogen bonds formation due to the functional groups and the chain flexibility [51]. 
Chitosan can interact with other chemical substances (ions, molecules, macromolecules) thanks to its particular chemical structure which makes it possible to glimpse capacities to interact, complex or absorb [52]. Chitosan can link functional derivatives on the macromolecular chains either by covalent, semi-covalent or non-covalent bonds (Figure 4).

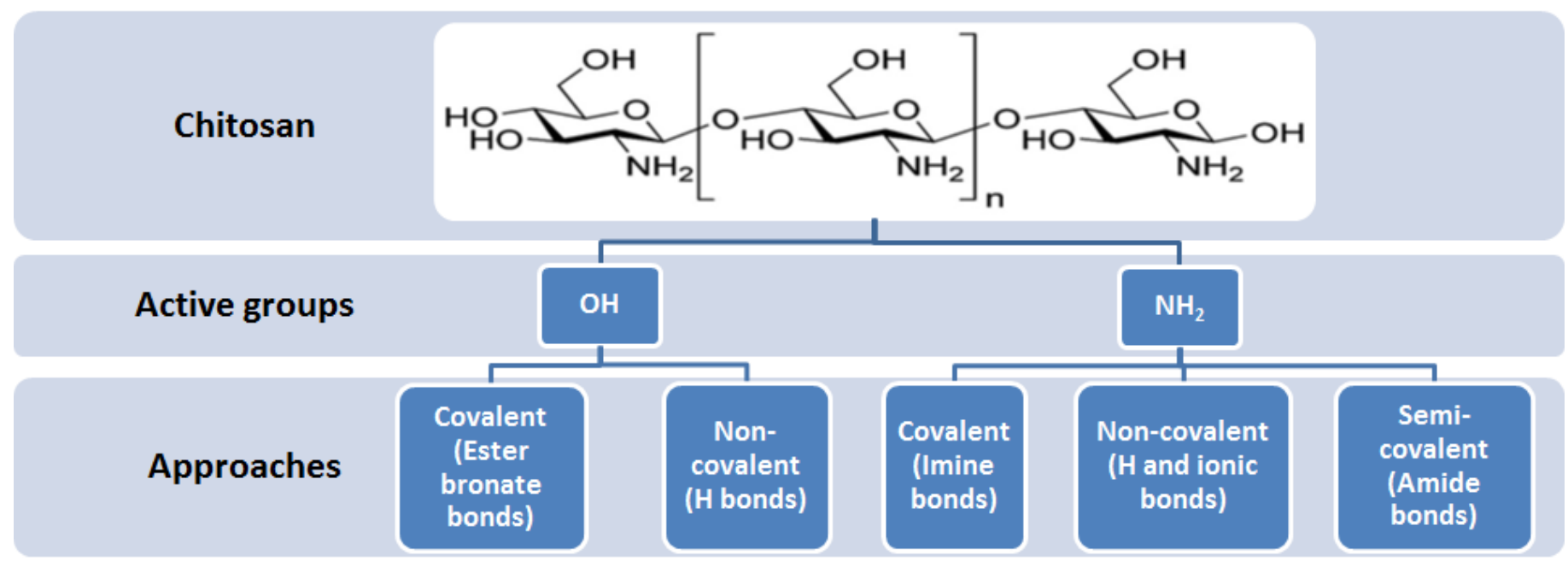

Figure 4: Different approaches to complexing chitosan.

At a $\mathrm{pH}<\mathrm{pKa}$, the amino functions of glucosamine are protonated. These can then develop ionic interactions such as the fixation of metallic anions, anionic dyes, and adhesion to negatively charged surfaces. These interactions also give to chitosan an excellent film-forming property [53]. At a basic $\mathrm{pH}$, the amine functions are not in ionized form and can then form hydrogen bonds or covalent amide or imine bonds with activated carboxylic acids and aldehydes, respectively. Concerning the semi-covalent approach, the amine groups are positively charged for $\mathrm{pH}$ values < 6.5 and can form ionic bonds with the carboxylic acid groups [54]. The alcohol functions of glucosamine can mainly develop hydrogen bonds or covalent bonds. To develop each of these approaches, it was necessary to take into account the acid-base constraints of glucosamine allowing the establishment of these specific bonds.

Also, these reactive groups offer to chitosan polymers many advantages and relevant properties (e.g. mucoadhesive properties, absorption enhancer) ; they are easily processed into gels, films, membranes, nanofibers and nanofibrils, scaffolds, beads, sponge forms, microparticles and nanoparticles [29,49]. In addition, chitosan possesses many more properties such as biocompatibility, biodegradability, low toxicity and good antimicrobial and antioxidant activities leading to numerous applications [28]. Table 2 summarizes the main properties of chitosan $[28,52]$.

Table 2: Properties of chitosan

Physical and chemical properties

Linear amino polysaccharide

Reactive amino and hydroxyl groups

Chelates many transitional metal ions

Rigid D-glucosamine structure

High hydrophilicity, crystallinity

Deprotonated amino group

Form hydrogen bonds intermolecularly

High viscosity

Soluble in water and organic solvents

Soluble in dilute aqueous acidic solutions

Polyelectrolytes (at acidic pH)
Biological properties Biocompatibility

Natural polymer

Bioadhesivity

Bioactivity

Nontoxic

Biodegradability

Antimicrobial activity

Antioxidant activity

Antiacid, antiulcer and antitumoral

Blood anticoagulants

Hypolipidemic activity 
Flocculating agent

Entrapment, filtration, separation and adsorption properties
Renewable

Film forming ability

Hydrating agent
14

\section{II.4. Chitosan solubility}

Chitin is insoluble in many organic solvents due to the presence of acetyl group with a hydrophobic nature [55]. Chitosan is the only commercial water-soluble cationic biopolymer and it is soluble in dilute acidic solutions at $\mathrm{pH}$ values above 6.5 but insoluble in neutral and alkaline aqueous solutions $[43,55]$. Table 3 , shows some solutions used for the solubilization of chitosan.

Table 3: Some solutions used for the solubilization of chitosan

\begin{tabular}{ll}
\hline Soluble & Insoluble \\
\hline Acetic acid $1 \%[36]$ & Sulfuric and phosphoric acids [36] \\
Formic acid $0.2-100 \%[36]$ & Any neutral and alkaline pH aqueous solutions [43] \\
Hydrochloric acid $1 \%[36]$ & \\
Dilute nitric, succinic, lactic and malic acids [43] & \\
Water [56] &
\end{tabular}

One of the most important properties of this polymer is the presence of the amine group with a pKa value of 6.5 in the carbonic chain. With this termination, chitosan indeed has an acid-base behavior in solution, as shown in Figure 5. It is reported that the pKa value increases with the ionic strength, thus widening the $\mathrm{pH}$ range in which chitosan is soluble [57]

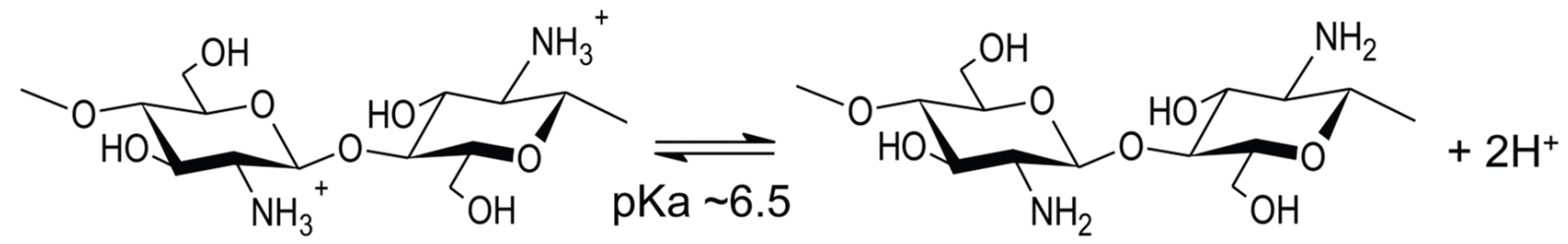

Figure 5: Behavior of chitosan according to the $\mathrm{pH}$ of the solution

So, at $\mathrm{pH}<\mathrm{pKa}$ the amino groups are positively charged which makes the chitosan a water-soluble cationic polyelectrolyte, and at $\mathrm{pH}>\mathrm{pKa}$ the biopolymer loses its charge and becomes insoluble [36]. Indeed, at low pH, the chain is polycationic. Repulsive electrostatic forces prevent the monomer associations which make chitosan soluble in solution. When $\mathrm{pH}$ increases, the chitosan loses its positive charge, the balance between the forces of attraction and repulsion is then disturbed [31,58]. As discussed previously, the solubility of chitosan in acidic medium is explained by the cationic character of its amine functions when they are protonated providing sufficient electrostatic energy to break the numerous hydrogen bonds and considerably improve the hydration of the chains. Therefore, the solubility of chitosan also depends on the distribution of the acetyl groups along the biopolymer chain and the DD value.

\section{II.5. Chitosan stability}

Chitosan is very sensitive to different experimental parameters that affect its stability; degree of deacetylation, molecular weight, polymer concentration, type of acid and its concentration are parameters to take into account in the experiments [57].

\section{- Temperature and $\mathrm{pH}$ effect}

The main factors affecting the behavior of $\mathrm{CS}$ and its physical properties are $\mathrm{pH}$ and temperature. $\mathrm{pH}$ affect the polymer properties due to the protonation and deprotonation of the amino groups [59]. High temperature $\left(>500^{\circ} \mathrm{K}\right)$ may cause thermal degradation of CS [60]. Also, it has been reported that heat treatment can change the way the chains of the polymer react; this is attributed to the influence of the ionic association of amine groups with alkanoic acids, such as formic, acetic, propionic, and butyric acid [61,62]. The mechanism may involve an initial depolymerization followed by interchain cross-linking when the amount of heat assimilated is sufficiently high [63]. 
Humidity is one of the factors affecting the behavior of chitosan. Studies show that exposing thin layers of chitosan to moist air causes considerable swelling of the film. After heating and then cooling to the ambient temperature of these layers, a dramatic decrease in thickness is recorded. These changes are not due to the oxidation or the thermal degradation of the films but it is suggested that the heating irreversibly releases the trapped water [64].

Furthermore, studies on chitosan-based sensors show that, probably, in an airy medium, oxygen molecules are chemically absorbed by chitosan (Equation 1). Once the film is subjected to a potential, the absorbed oxygen molecules react with the free electrons forming ionic species such as $\mathrm{O}_{2}^{-}$and $\mathrm{O}^{-}$(Equation 2-3), causing an increase in resistance to charge transfer until the oxygen molecules are saturated. In the presence of water, the molecules in contact with chitosan react with $\mathrm{O}^{-}$to produce $\mathrm{O}_{2}$ and release the electrons participating in the modification of the response of the sensor (Equation 4).

$\mathrm{O}_{2} \rightleftarrows \mathrm{O}_{2}$ (absorbed)

$8 \mathrm{O}_{2}$ (absorbed) $+\mathrm{e}^{-} \longleftrightarrow \mathrm{O}_{2}$

$\mathrm{O}_{2}^{-}+\mathrm{e}^{-} \longleftrightarrow 2 \mathrm{O}^{-}$

CS- $-\mathrm{NH}_{2}+2 \mathrm{O}^{-}+\mathrm{H}_{2} \mathrm{O} \rightleftarrows$ CS-NH $\mathrm{NH}_{2}+\mathrm{O}_{2}+\mathrm{H}_{2} \mathrm{O}+2 \mathrm{e}^{-}$

In addition to reacting with $\mathrm{O}^{-}$, bonds can be formed between the oxygen of the water molecules and the hydrogen of the amino groups of chitosan (Fig.6). These connections act as electrical bridges creating a surface tension facilitating the movement of the electrons [21].

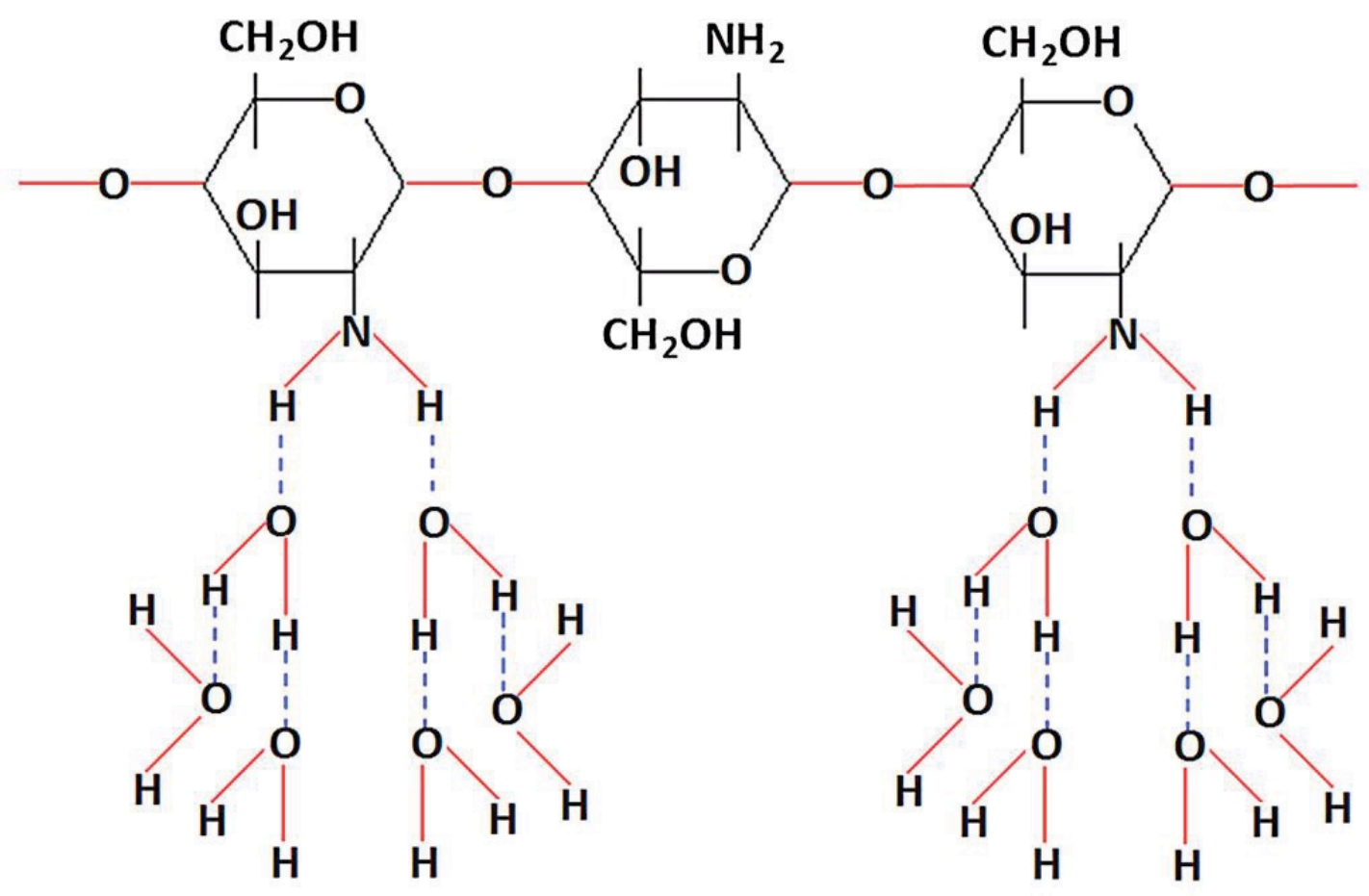

Figure 6: Formation of hydrogen bridges by reaction between water molecules and CS amino groups [21]

II.6. Chemical modification of chitosan

Chitosan, by its hydroxyl functions and its primary amine, offers multiple possibilities of chemical functionalization, and allows easy modifications including $\mathrm{N}$ substitution, $\mathrm{O}$ substitution and free radical graft copolymerization. These modifications have been proposed in order to improve the intrinsic properties of CS (pore size, mechanical strength, chemical stability, hydrophilicity and also biocompatibility) or to give new properties [65].

Chemical crosslinking is used to improve the stability and compatibility of chitosan and enhance its mechanical properties. Amine and hydroxyl active groups on the biopolymer chain allow reactions with some chemical agents while undergoing structural changes. These modifications are due to the creation of covalent bonds, $-\mathrm{OH}$ is more likely to participate in a nucleophilic reaction than amine because of the stronger electronegativity of oxygen $[66,67]$. Several crosslinking agents have been established with chitosan (figure 7) including glutaraldehyde and glyoxal [68], N,N'-methylenebisacrylamide, 2-(chloromethyle) thiirane, ethylene glycol diglycidyl, 
sulfuric acid [66], genipin [69], sodium tripolyphosphate [70], (3-glycidoxypropyl)trimethoxysilane [71], diisocyanates and epichlorhydrin [72].

The chemical modification of the polymer makes it possible to modify its physical and chemical properties. Many modifications are possible, in particular the grafting on the amine function of various chemical groups. The primary amine comprising a non-binding doublet is a good nucleophile that will allow nucleophilic addition/elimination reactions on electrophilic carbons such as aldehydes, ketones and carboxylic acid.

Many studies have examined the modification of chitosan. Chitosan has in particular been functionalized with benzaldehyde [73], 4nitrobenzoyl chloride and with glutaraldehyde [74], a compound having two aldehyde functions making it possible to create a covalent bridge between chitosan and DNA fragments [26] or enzymes [75].

A widely used synthetic route for the biofunctionalization of chitosan is by forming an amide bond between the primary amine of chitosan and the carboxylic acid function of the biomolecule to be fixed. This bond is difficult to implement and requires the prior activation of the carboxylic acid function carried out by the 1-ethyl-3- (3-dimethylaminopropyl) carbodiimide and $\mathrm{N}$-hydroxysuccinimide (EDC/NHS) pair. This (non-detailed) activation mechanism consists of forming an intermediate ester between NHS and the carboxylic function [76].<smiles>O=CCCCC=O</smiles>

Glutaraldehyde<smiles>COC(=O)C1=COC(O)C2CC=C(CO)C12</smiles>

Genipin<smiles>ClCC1CO1</smiles>

Epichlorohydrin<smiles>CO[Si](C)(O)CCCOCCOCO</smiles>

(3-glycidoxypropyl)trimethoxysilane<smiles>NOP(=O)(O)P(=O)(O)P(=O)(O)ON</smiles>

Sodium tripolyphosphate

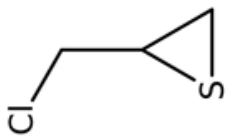

2-(Chloromethyle)thiirane<smiles>O=CC=O</smiles>

Glyoxal<smiles>C=CC(=O)NCNC(=O)C=C</smiles>

\section{$\mathrm{N}, \mathrm{N}^{\prime}$-methylenebisacrylamide}<smiles>C(COCC1CO1)OCC1CC1</smiles>

Ethylene glycol diglycidyl<smiles>O=S(=O)(O)O</smiles>

Sulfuric acid

Figure 7: Different types of crosslinking agents for chitosan

\section{II.7. Conclusion}

As presented in this part, chitosan is an abundant biosourced polymer, presenting functional groups that can be easily chemically modified. It is soluble in aqueous solutions and it is well known to preserve the activity of biological molecules such as proteins [15]. Most of the template molecules are soluble in aqueous media, then these properties of chitosan are of interest for the preparation of molecule template-polymer complex. The classical monomers used for MIP preparation, mainly vinylic and acrylic ones [11] are not soluble in aqueous solution. This point could be deleterious for some template molecules such as peptides and proteins. Due to its natural origin, chitosan is biodegradable, which is not the case of classical monomers that are not compatible with circular economy.

\section{MIPs as recognition elements in electrochemical sensors}

\section{III.1. General principle of MIPs}

The molecular imprinting technique illustrated in Figure 8 makes it possible to prepare polymers capable of selectively recognizing a chosen molecule(s) commonly called target molecule(s) or template(s). 


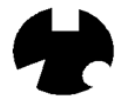

Template 1

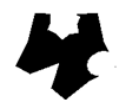

Template 2

Pre-polymerization
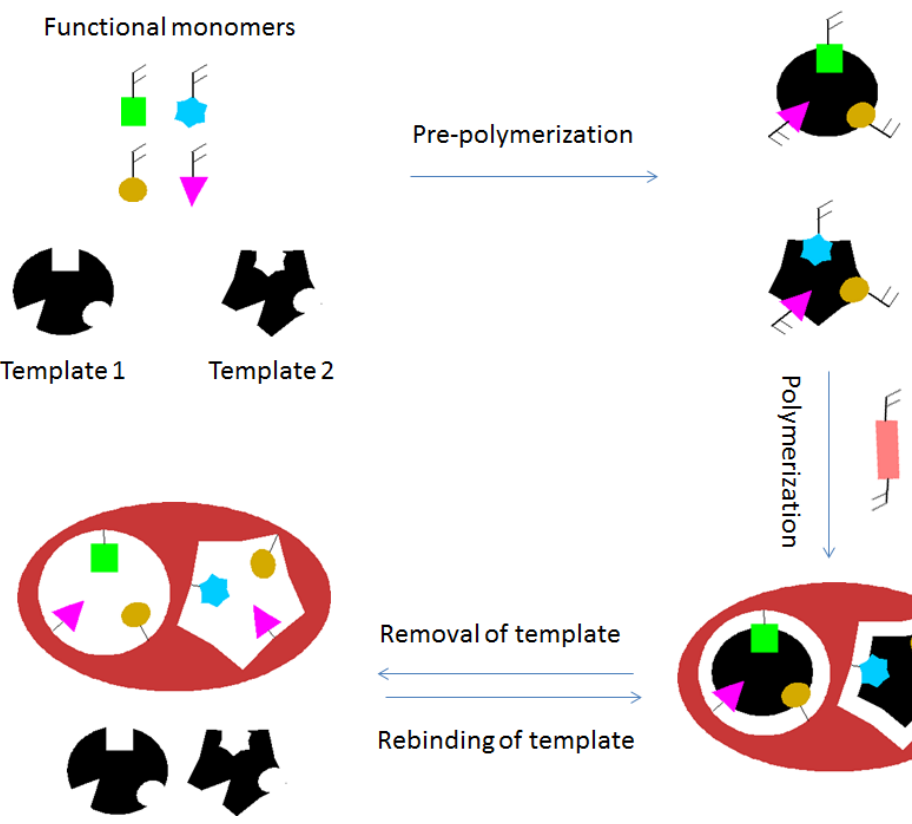

Removal of template

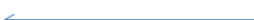

Rebinding of template
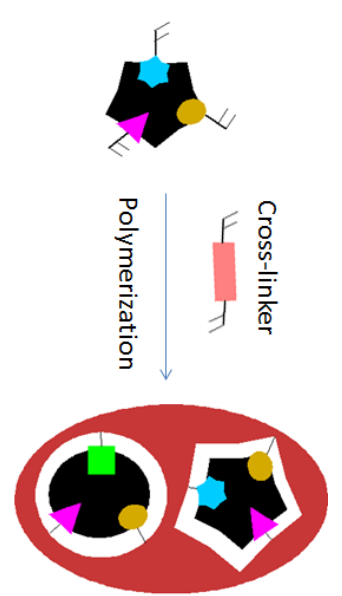

Figure 8: Schematic of molecularly imprinted polymers for two different templates.

step1: Pre-polymerization. Step 2: Polymerization and cross-linking. Step 3: Removal of template. Step4: Recognition

Molecularly imprinted polymers (MIPs) are artificial receptors prepared with a template, functional monomer and cross-linking agent. The functional monomer interacts with the template forming a complex called "pre-polymerization complex". In the presence of a crosslinking agent, the complex is copolymerized in order to obtain a crosslinked polymer. After polymerization, the groups of functional polymers are held in position to form a cast-type shell. The last step is then to extract the target molecules from the polymer. Template molecules are removed by electrochemical or chemical extraction to disrupt the interactions between the template and the monomers $[77,78]$. In essence, synthetic polymeric materials with specific recognition sites, complementary in shape, size and functional groups to the template molecule are formed, through an interaction mechanism based on molecular recognition.

\section{III.2. Response of MIPs electrochemical sensor}

For a sensor to be effective, it must generate a measurable, and if possible quantifiable, physical signal during the interaction between the target molecule and the MIPs (Figure 9).

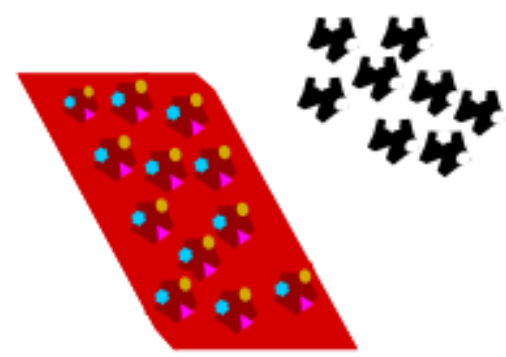

Recognition
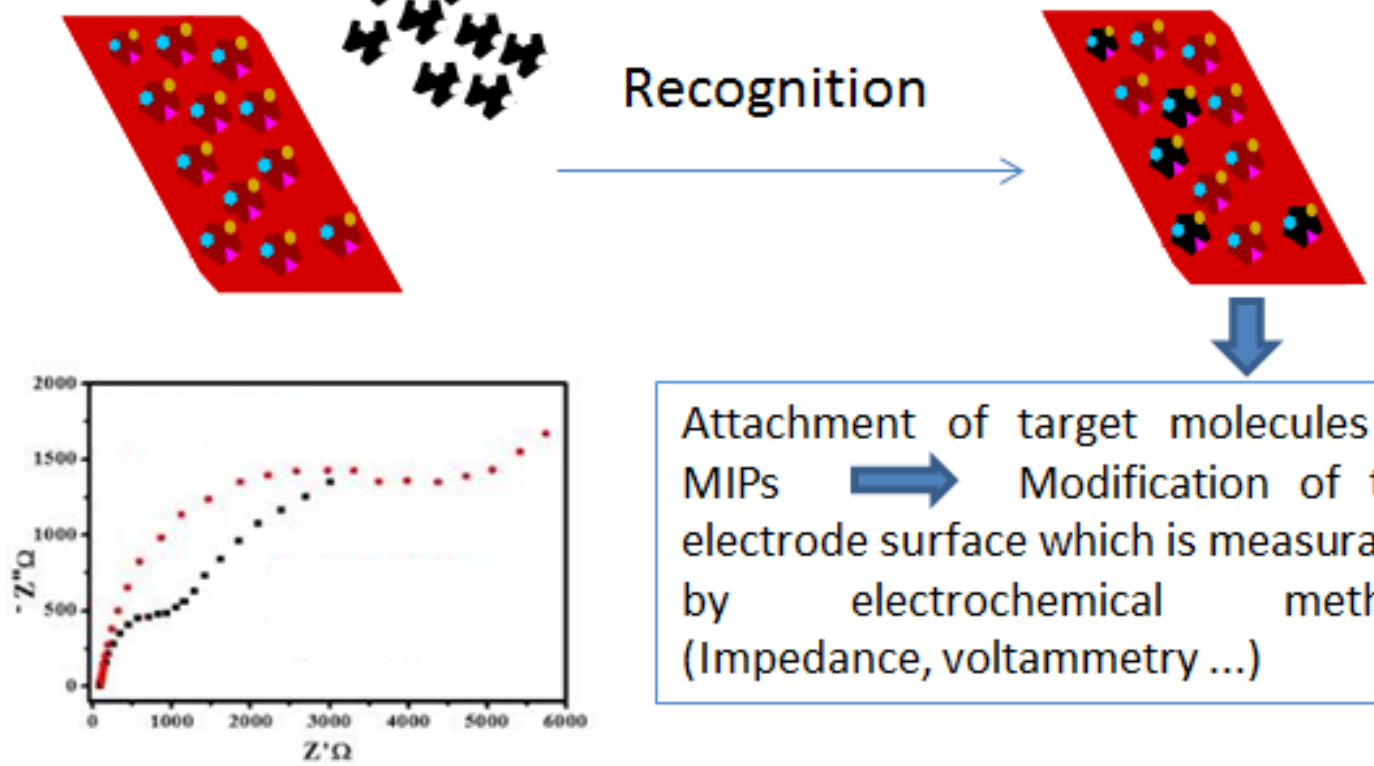

Attachment of target molecules to

MIPs $\Longrightarrow$ Modification of the electrode surface which is measurable by electrochemical method (Impedance, voltammetry ...)

Figure 9: Electrochemical response of MIPs sensor. 
Selectivity, sensitivity, stability, reuse, response time, etc., are the main parameters in the design of sensors based on MIPs. These parameters depend on both the properties of the MIP and its ability to interact with the analyte under the required conditions. These parameters also depend on the sensitivity of the transducer and its ability to monitor the interaction process and transform it into a measurable signal. It is therefore essential to choose not only a good combination between these two components but also the electrochemical technique used.

Electrochemical measurements implemented in the case of sensors based on MIPs are very often conductimetry, potentiometry, amperometry, voltammetry and impedancemetry. Conductometric sensors are based on the measurement of the change in conductivity resulting from the recognition of the target molecules by the MIPs. A potentiometric sensor measures the potential difference between the working electrode functionalized with MIPs and a reference electrode at zero current. The signal in amperometric devices depends on the rate of charge transfer at the surface of the electrode. A voltammetric sensor measures the variation of the intensity of the current in an interval of the applied potential. The impedance measurement is based on the measurement of the variation in the charge transfer resistance of the MIPs. It is possible to link the results of the measurements to the physical and chemical properties of the MIP-template interaction, and this by modeling the response by suitable equivalent electrical circuits.

The choice of measurement technique is generally guided by the electrochemical properties of the target molecule. When the target is electroactive, its presence in the medium to be analyzed will contribute to the modification of the intensity of the current; this change could be followed by amperometry or voltammetry. If the target does not present any redox properties, the presence of the target will cause a change in the MIP film, a behavior generally monitored by conductimetry or impedance.

\section{III.3. Synthesis parameters of CS-MIPs}

\section{- Preparation of CS solution}

The most commonly used acid for dissolving chitosan is acetic acid in aqueous solution, since the films of chitosan obtained with acetic acid as solvent have properties to water [79]. Acid solutions concentrated at high temperatures can depolymerize chitosan [80], so, CS is generally prepared with diluted acid.

\section{- Template}

The choice of template during the synthesis of molecularly imprinted chitosan is of major importance, it must form the largest number of specific well-defined interactions. Ideally, these interactions with the monomer should be strong to ensure better effectiveness. In most studies, the molecule of interest is the template. However, for certain reasons such as rarity, high price, toxicity, difficulty in handling, etc, the target molecule may be replaced by a molecule which is structurally and chemically analogous during synthesis. For example, 2,4-dinitrotoluene (2,4-DNT) is used to form specific sites for the analysis to nitro explosives, as 2,4-DNT has a similar structure with nitro explosives [81]. However, one must be aware of the disadvantages of using a model with a structural similarity to the analyte and ensure that the matrix does not interfere in the quantification [82].

The template to be used requires taking into account its structure and its functional groups, which make it possible to form bonds with active groups of chitosan throughout the formation process of the template/biopolymer complex. Likewise, the size of the template plays a role in the specificity of the cavities formed during imprinting. Indeed, for a high molecular weight template, there is a risk that the small molecules might penetrate the cavities developing non-specific interactions [83]. In addition, the larger templates are less rigid and do not facilitate the creation of well-defined cavities. Also, large molecules such as peptides and proteins do not easily penetrate the polymer network to occupy the cavities [84]. The imprinting of small molecules, like pesticides and pharmaceuticals, is well established in the synthesis of MIPs and considered routine; however the printing of much larger structures remains a challenge.

\section{- Crosslinker}

Crosslinking is a key step in the synthesis of MIPs. The type of crosslinking agent and its proportion relative to the amount of functional monomer are important in controlling the morphology of the polymer matrix and the selectivity of the cavities formed after the extraction of the template, they allow:

$\checkmark$ Precise control of the imprinting of the template.

$\checkmark$ Complementary interactions with the target.

$\checkmark$ The mechanical stability of the imprints obtained and of the polymer.

$\checkmark$ The formation of a rigid matrix, resistant to high temperature and pressure conditions and inert towards acids and bases [85].

For a MIPs synthesized in a polar solvent, it is important to choose a hydrophilic crosslinker to facilitate contact with the surface of the polymer. Also, the use of MIPs crosslinked with a hydrophobic agent remains unstable in aqueous media.

To crosslink the chitosan used in sensors based on MIPs, two methods are used; either the crosslinking agent is mixed with the template/polymer complex before deposition on the working electrode surface; in this case the crosslinking agent/functional monomer 
ratio is very important [86]. The second method is based on the deposition of the template/polymer complex on the electrode and then impregnating the modified electrode in the cross-linker solution. Here, the concentration of the crosslinking solution and contact time define the properties of the prepared MIPs [87].

\section{III.4. Principle of the electrodeposition of chitosan}

The ability to create devices like sensors and biosensors requires easy methods to precisely control surfaces. A variety of techniques can be used to produce the desired structures. The integration of a chitosan-MIP with the transducer area is a crucial step in the fabrication of the sensor. The biopolymer material must adhere well to this surface without dispersing or detaching under any conditions. The properties of chitosan have been used to make membranes, thin films and three-dimensional structures by various methods such as drop coating [88], microcontact, complexation with anionic polyelectrolytes [26].

The $\mathrm{pH}$-sensitive solubility and properties of chitosan have also been used to make membranes, thin films and three-dimensional structures. Chitosan changes from a soluble state in acid solution to a precipitated hydrogel state when the $\mathrm{pH}$ of the solution increases. CS can be easily poured, producing membranes and films which can be converted into insoluble networks by neutralization. The cast chitosan membranes/films can be made insoluble over the entire pH range by covalently crosslinking the chitosan chains by amide and imine interactions.

Electroaddressing is used for the deposition of chitosan in the field of electrochemical sensors; it consists in applying a cathodic voltage to the surface of an electrode. Electrodeposition has the advantage of being a simple, fast and low cost technique. It is an in situ process that combines precipitation and immobilization. The electrodeposition of chitosan makes it possible to obtain very porous films in a spatially selective and modeled manner [89]. This technique has been used successfully to deposit chitosan films on conductive electrodes $[90,91]$. More specifically, the chitosan can be electrodeposited on the surface of a cathode by the mechanism illustrated in the figure 10 .

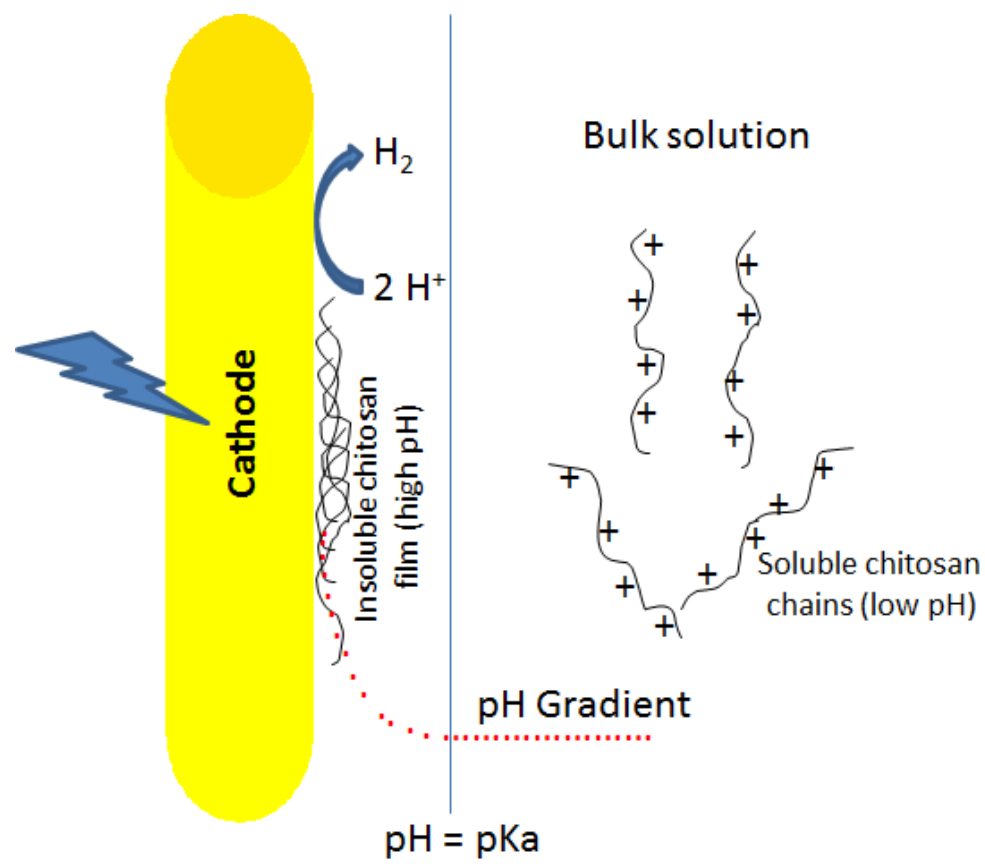

Figure 10: chitosan electrodeposition mechanism

Local $\mathrm{pH}$ is increased, close to the cathode surface, due to the electrochemical reduction of water, according to the following reaction:

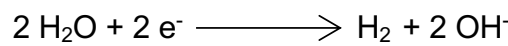

The $\mathrm{pH}$ varies as a function of the relative rates of hydroxyl ion generation and hydroxyl ion diffusion from the interfacial region. The hydroxyl ions generated are adjusted by the voltage applied to the surface of the electrode. In the presence of the slightly acidic solution of chitosan, a pH gradient is established in the vicinity of the surface of the cathode. In localized regions with a high $\mathrm{pH}$ above 6.5 the chitosan is deprotonated and becomes insoluble. Depending on the conditions, this causes precipitation of the polymer and the formation of a homogeneous membrane on the surface of the cathode [91]. $\mathrm{A} \mathrm{pH}$ gradient near the electrode allows the precipitation of chitosan during the application of the potential, $\mathrm{pH} 5$ being considered as the optimal $\mathrm{pH}$ of the electrodeposition.

\section{III.5. Chitosan electrodeposition techniques}


14 The two most commonly used techniques for the electrodeposition of chitosan are cyclic voltammetry (CV) and chronoamperometry 15 (CA).

17 Figure 11 shows the electrodeposition voltammograms of chitosan on gold macroelectrodes at pH 5 [92]. A CV of the chitosan solution 18 prepared in $0.1 \mathrm{M}$ acetic acid was carried out with a potential varying between $-1.5 \mathrm{~V}$ and $0.5 \mathrm{~V}$ at a scan rate of $80 \mathrm{mV} / \mathrm{s}$. There is a 19 cathodic peak characterizing the electrodeposition of the polymer. The peak intensity gradually decreases according to the scan 0 number, a sign of precipitation of the polymer on the surface of the electrode. Beyond a few scans, the intensity of the peak does not 1 vary, which makes it possible to fix the number of scans. This test shows that a constant voltage between $-1.3 \mathrm{~V}$ and $-1.1 \mathrm{~V}$ is optimal 2 for chronoamperometry deposition, preventing an excessive yield of hydrogen gas affecting the deposition and adherence of the 3 polymer.

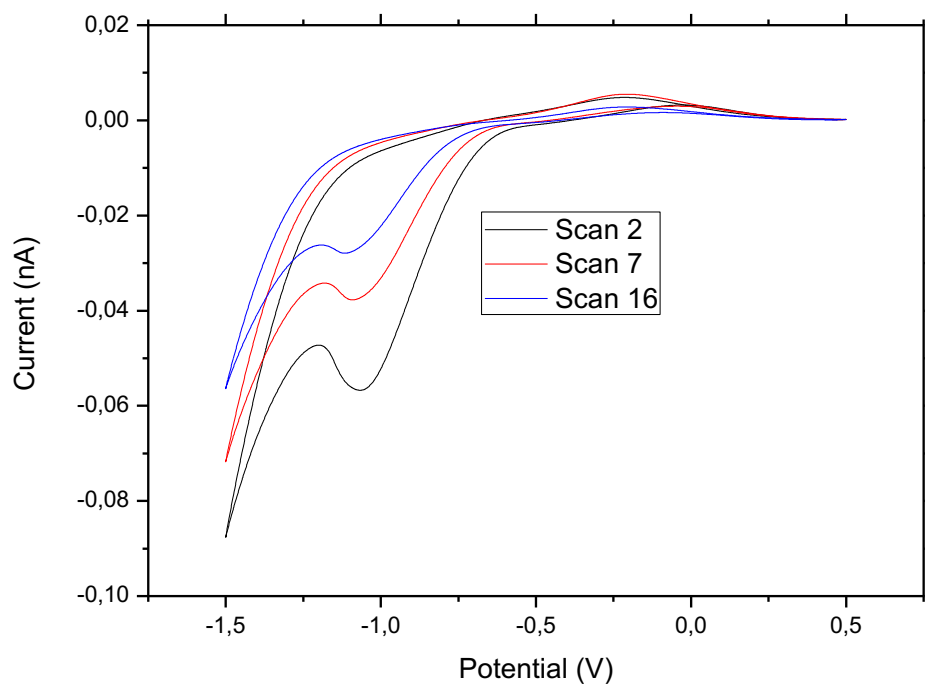

Figure 11: $\mathrm{CV}$ of electrodeposition of chitosan on gold microelectrode at $\mathrm{pH} 5$ and a scan rate of $80 \mathrm{mV} / \mathrm{s}$.

Figure 12 shows the curves obtained during the electrodeposition of chitosan by CA on gold macroelectrodes at $\mathrm{pH} 5$ and an applied voltage of $-1.1 \mathrm{~V}$ [93]. After a decrease in the negative current, a plateau is observed, a sign that the reaction by diffusion of $\mathrm{H}^{+}$at the surface of the electrode has been limited. The formation of this plateau indicates the effective deposition of the polymer, which makes 1 it possible to optimize the time of the electrodeposition. 


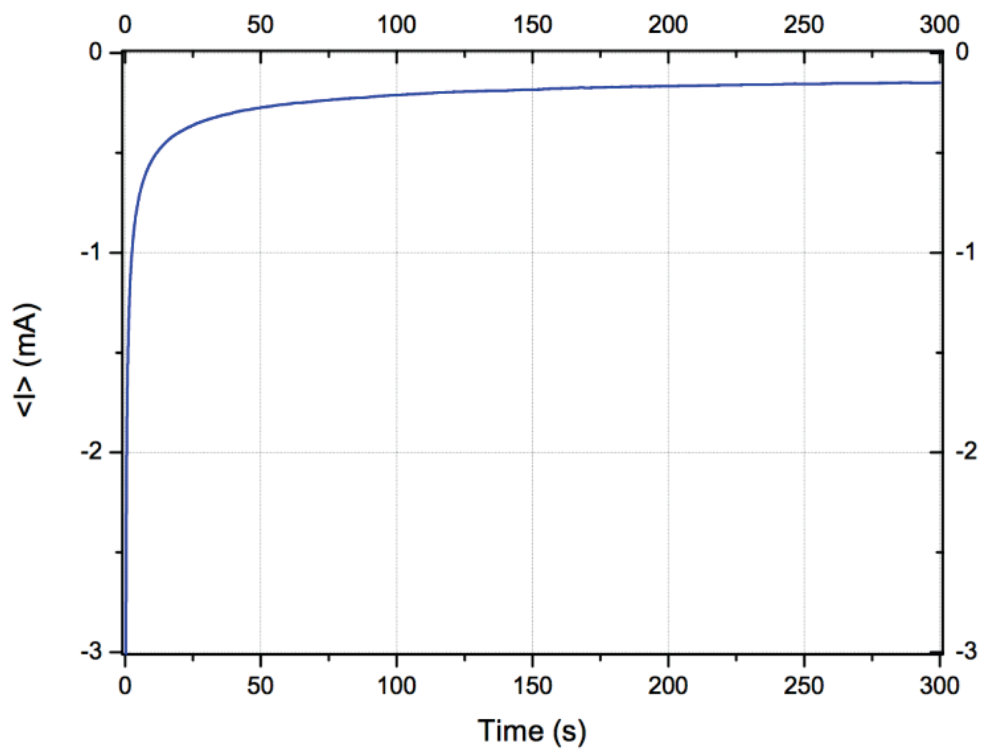

Figure 12: CA of electrodeposition of chitosan on gold microelectrode area at pH 5 and potential of $-1.1 \mathrm{~V}$.

4

Chitosan can be deposited in a controllable manner. The thickness of the electrodeposited chitosan film can vary as a function of the $\mathrm{pH}$ of the solution and electrochemical deposition conditions such as the time and the potential applied for the CA, the potential interval, the number of cycles and the scan rate for $\mathrm{CV}$.

\section{III.6. Removal of the template}

The last step in the MIP process is to extract the target molecules from the biopolymer. Extraction of the imprinted model is an important step in the manufacture of MIPs, and for this purpose, numerous protocols have been established. The choice of procedure must take into account the efficiency of the extraction while maintaining the structure without causing any degradation of the matrix (by solvent, temperature, etc.).

Templates are removed from the MIPs by electrochemical or chemical extraction, allowing disturbance of the interactions of the prepolymerization complex. Indeed, non-covalent interactions such as hydrogen interactions can be "broken" by washing with solutions of different $\mathrm{pH}$ [94].

However, this step does not lead to the complete extraction of the template from the polymer; more than $1 \%$ of the template used during the synthesis of MIPs remains bonded to the polymer even after intensive washing [95]. As a result, not only is there a decrease in active sites, but also large dosing errors can then occur due to the slow release of the remaining molecules when using MIPs [82].

\section{III.7. MIPs electrochemical sensors based on chitosan}

Due to its macromolecular structure (carrying an excess of amine and hydroxyl groups), its physico-chemical and biological properties, the use of chitosan in molecularly imprinted polymers has attracted considerable attention. The fact that chitosan has an affinity for various compounds and the possibility of complexing the template or of undergoing chemical modifications by means of different approaches (non-covalent, semi-covalent, covalent) can be easily exploited for the construction of MIPs.

Due to its relevant structural benefits of being easily transformed into gels, films, membranes, nanofibers and nanofibrils, scaffolds, beads, sponge forms, microparticles and nanoparticles, molecular imprinted chitosan is widely used in various applications such as solid-phase extraction [19], selective separation of proteins [96], therapeutic studies [97,98], sensors [99], etc. The properties of MIPs such as specificity and high stability, compatibility with microfabrication technology and low cost make them promising alternatives to the antibodies and other natural receptors usually used [100].

Several sensors have been developed using MIPs as mentioned above such as electrochemical, colorimetric, fluorescent sensors, etc. Given the predominance of electrochemical sensors on the market due to their simplicity, sensitivity, ease of implementation and generally low measurement costs, this review will focus on the development of electrochemical sensors based on molecularly imprinted chitosan (CS -MIPs). Many successful examples of the development of electrochemical sensors based on chitosan-MIPs for different templates such as metabolites (dopamine, L-dopa, glucose, urea), pesticides (trichlorphon, glyphosate), medications (clenbuterol, epinephrine) and phenolic compounds ( $\mathrm{p}$-nitrophenol, 2,4,6 tribromophenol, bisphenol A, catechol), are reported in Table 4. The detected molecules generally present a molecular weight between 100 and $200 \mathrm{~g} / \mathrm{mol}$. The common characteristics of these molecules is that they present hydroxyl and amine groups in their structure. Ion-imprinted sensors based on chitosan have also 
been developed for the detection of chromium (VI), cadmium and copper, due to the ion coordination with hydroxyl and amine groups in the glucosamine units.

Electrochemical sensors combined with molecularly imprinted chitosan showed good performance. The proposed sensors exhibited a good linear response towards several targets with a low detection limit, good selectivity, reproducibility, stability and reusability. The preparation procedures presented are relatively simple, convenient and provided rapid and economical methods [101-103].

Pulse Differential Voltammetry (DPV) is the most used electrochemical technique in MIP-based sensors. The results obtained show low detection limits, reaching $10^{-12} \mathrm{M}$ for the target molecule urea[104], and a slightly higher LOD in the case of dopamine $\left(10^{-11} \mathrm{M}\right)$ [77]. LOD is in the order of $10^{-7}$ to $10^{-9} \mathrm{M}$ with phenolic compounds $[56,78,101,105]$. The majority of these sensors can be reused up to 9 or 10 times [78,102-104,106], and others less for example 5 times with the target molecules 2,4,6-tribromophenol [105] and copper ions [107].

CA and CV are used in several studies. The detection limits are between $10^{-5}$ and $10^{-9} \mathrm{M}[24,25,108,109]$. Some sensors have been regenerated 9 times [108,110], and others less, for example 7 times in the case of bisphenol A [109], 3 times with catechol [24,25]. The lowest detection limit recorded is $10^{-21} \mathrm{M}$. The technique used was Square wave voltammetry (SWV) for the detection of bisphenol A [111]. Another, of $5.9 \times 10^{-18} \mathrm{M}$, has been described using electrochemical impedance spectroscopy, for the detection of glyphosate (EIS) [92].

A MIP sensor, using CV in the presence of $\left[\mathrm{Fe}(\mathrm{CN})_{6}\right]^{3-14-}$ is presented by Y.-P. Chen et al (Fig.13). The electrochemical sensor was constructed based on chitosan molecularly imprinted films, which were prepared by electrodeposition of chitosan in the presence of template (urea) using $\mathrm{CA}$ at $-1.1 \mathrm{~V}$ for $3 \mathrm{~min}$ on the Au disk electrode for the determination of urea. In order to elute the template molecules, the (urea+CS)/Au was placed in $\mathrm{KCl}$ solution. The sensor was characterized using $\mathrm{CV}$ in $\left[\mathrm{Fe}(\mathrm{CN})_{6}\right]^{3-14-}$ solution to determine the urea indirectly in the range from $10^{-8}$ to $4 \times 10^{-5} \mathrm{M}$ with a detection limit of $5 \times 10^{-9} \mathrm{M}$. The sensor offers great potential for clinical diagnosis applications [108].
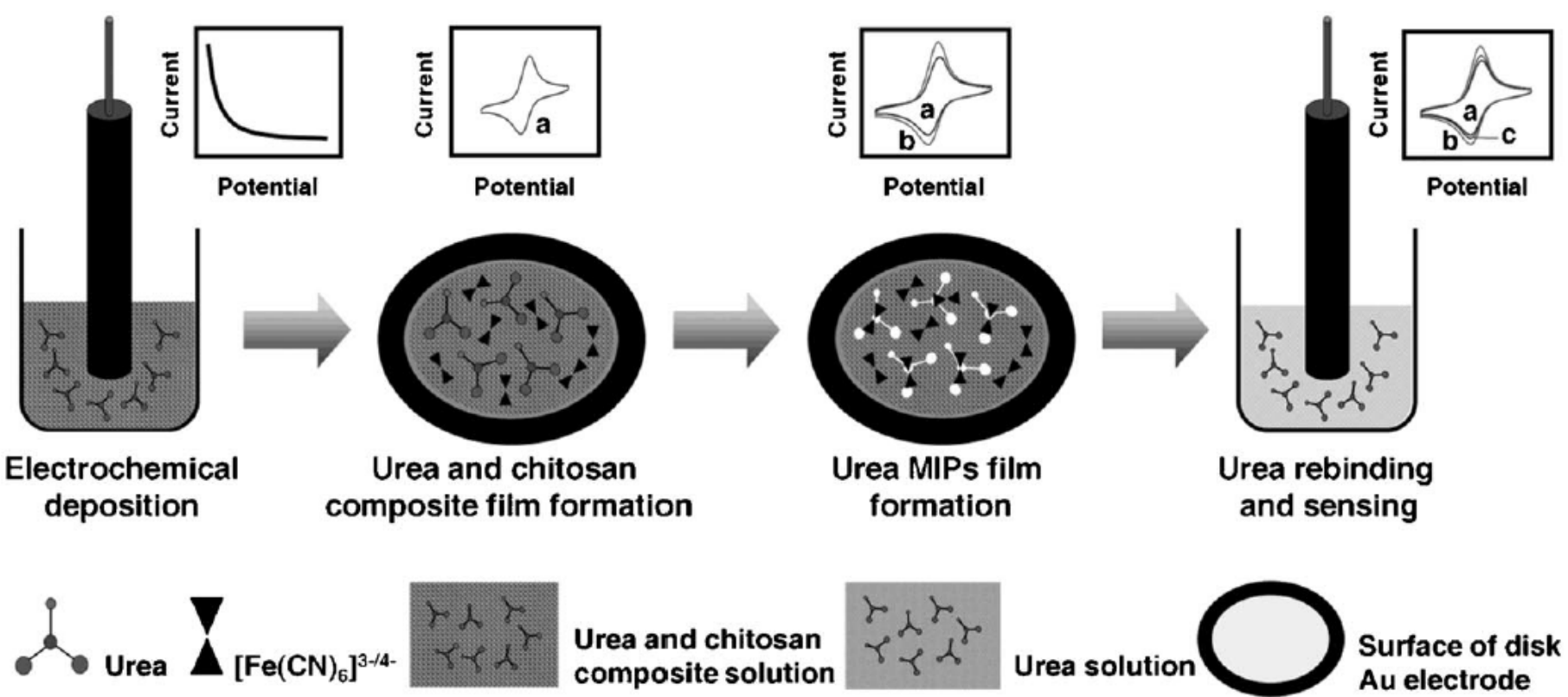

Urea and chitosan composite solution
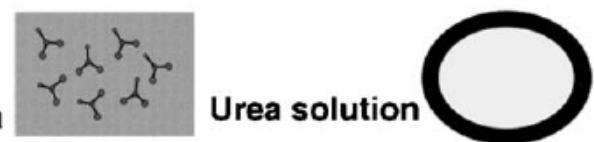

Surface of disk Au electrode

Figure 13: Schematic illustration of a MIP electrochemical sensor fabrication for the detection of urea.

\section{III.8. Nanomaterial doped-CS}

The electrochemical performance of electrodeposited CS film on the surface of the working electrode is limited by poor electrical conductivity. Indeed, due to the high degree of crystallinity that the polymer has, conductivity is low, which hinders the redox process [25]. To overcome this problem, the use of nanomaterials with electroactive functionality is of great interest in the development of electrochemical sensors based on molecularly imprinted chitosan, due to the fact that nanomaterials can improve the electron transfer between the electrode surface and the solution, so improving the sensitivity of chitosan-based sensing material. Nanomaterials such as gold nanoparticles [103], silver nanoparticles [86], $\mathrm{CuCo}_{2} \mathrm{O}_{4}$ carbon nanocomposites [112], ZnO nanoparticles [113], acetylene black [101], carbon nanotubes [25], Graphene [114], multiwalled carbon nanotubes [110] have been applied to modify electrode because of their excellent electrocatalytic activity.

An example of a chitosan-graphene based sensor is that by S. Wu et al [106] in which the fabrication process sensor is based on the electrodeposition of the chitosan-graphene nanocomposite and the template $(\mathrm{Cr}(\mathrm{VI}))$ on the Au disk electrode, for the determination of $\mathrm{Cr}(\mathrm{VI})$. The different steps for the fabrication of the MIP-based sensor are presented in Figure 14. Electrodeposition was performed using $\mathrm{CA}$ at $-1.2 \mathrm{~V}$ for $180 \mathrm{~s}$. Glutaraldehyde was used to crosslink the chitosan-graphene-Cr (VI) film. The obtained imprinted 
electrode was successively rinsed with acetone/water to remove the template. The detection was performed using DPV in a linear range from $10^{-9}$ to $10^{-5} \mathrm{~mol} / \mathrm{L}$, with a low detection limit of $6.4 \times 10^{-10} \mathrm{~mol} / \mathrm{L}$. The proposed sensor was successfully applied to the detection of $\mathrm{Cr}(\mathrm{VI})$ ions in tap water and river water.

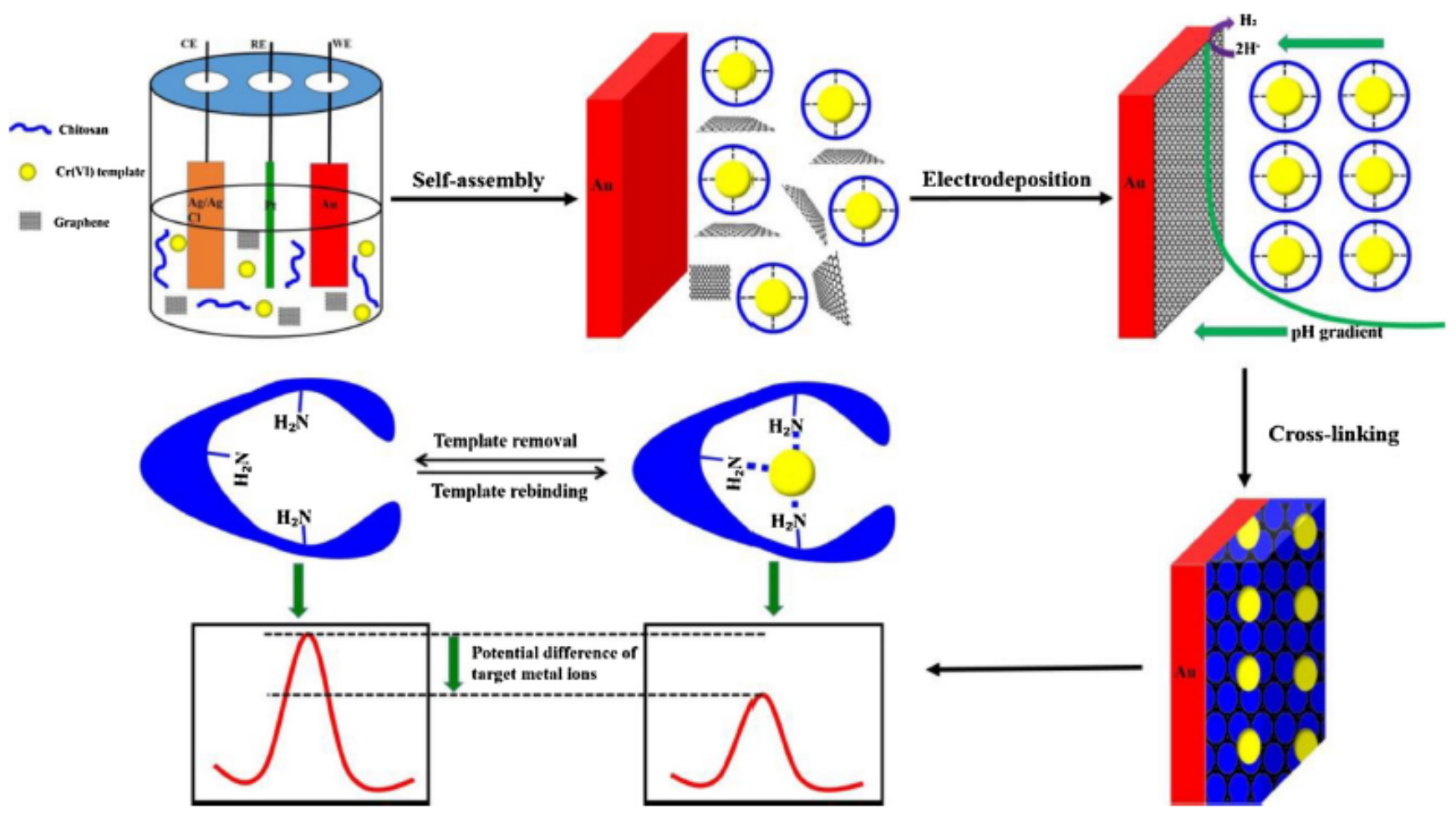

Figure 14: Schematic representation of the fabrication process of chitosan-graphene MIP sensor for Cr (VI) detection.

In the work of A. Fatoni et al (Fig.15), a MIP sensor was prepared by dropping onto the gold rod electrode the mixture of CS, acrylamide, $\mathrm{N}, \mathrm{N}$-methylenebisacrylamide, graphene, ferrocene and microalbumin as template. The template was removed from the modified electrode by soaking in acetic acid-sodium dodecylsulfate solution. The specific imprinted surface was used to detect microalbumin from $1.5 \times 10^{-9}$ to $1.5 \times 10^{-7} \mathrm{M}$ via a redox mediator (ferrocene), entrapped in the cryogel, using differential pulse voltammetry (DPV). The limit of detection was $7.7 \times 10^{13} \mathrm{M}$ and the excellent performance of the biosensor was confirmed by analyzing microalbumin in urine samples [102]. 
CS, AM, BAM

Graphene

Ferocene

HSA

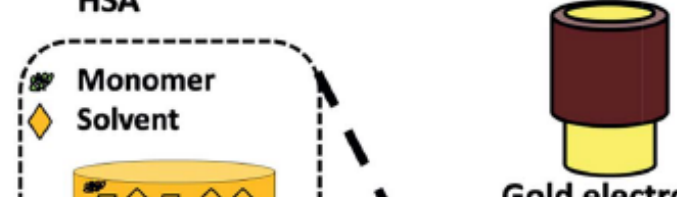

APS

$\rightarrow$

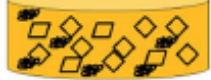

Cryogelation

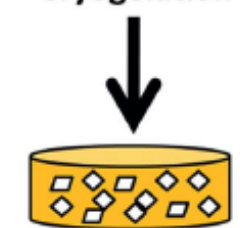

1

Gold electrode

Thawing

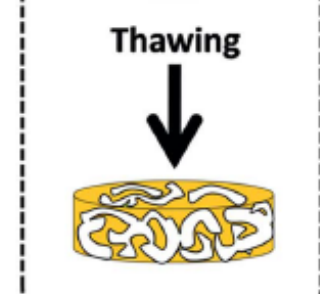

1

V

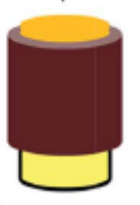

1

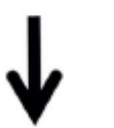

Template
Removing

Acetate, SDS

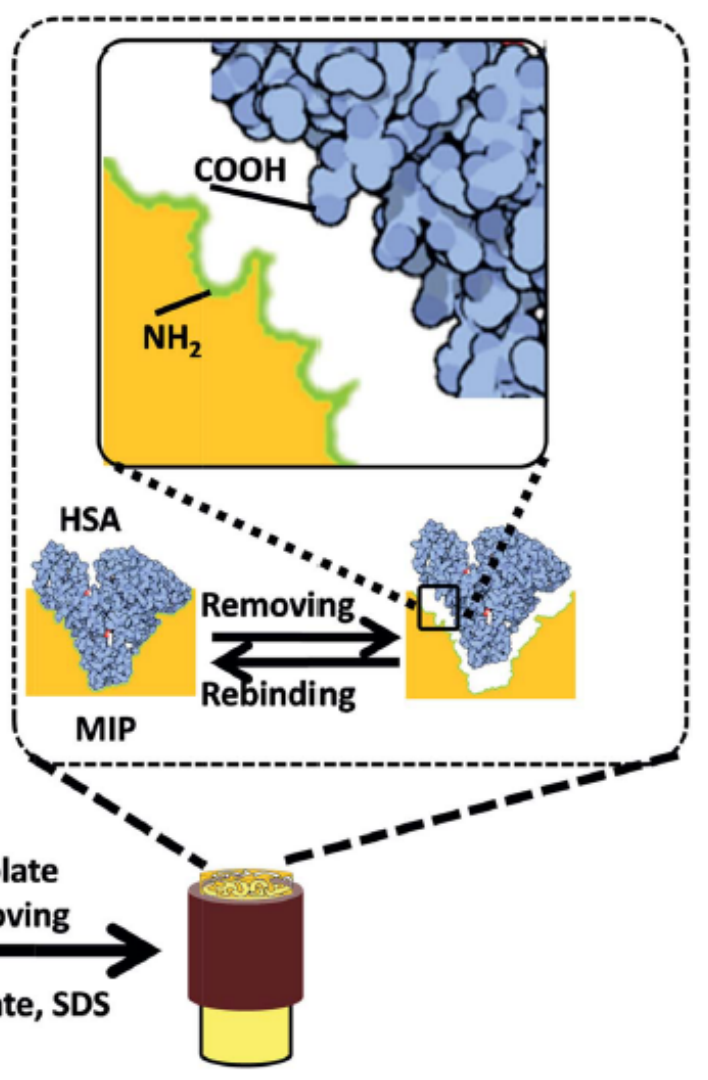

Figure 15: Schematic representation of the fabrication process of MIP sensor chitosan grafted polyacrylamide MIP cryogel with graphene and entrapped ferrocene for the detection of microalbumin. 
Table 4: Electrochemical sensors based on CS-MIPs.

\begin{tabular}{|c|c|c|c|c|c|c|c|c|c|}
\hline $\begin{array}{l}\text { Detection } \\
\text { technique/ } \\
\text { Electrode/ } \\
\text { Supporting } \\
\text { electrolyte }\end{array}$ & $\begin{array}{l}\text { Target } \\
\text { molecule/ } \\
\text { Template }\end{array}$ & $\begin{array}{l}\text { Composition/ } \\
\text { Deposition } \\
\text { technique }\end{array}$ & Cross-linking & $\begin{array}{l}\text { Extraction of } \\
\text { template }\end{array}$ & Samples & Linear range & $\begin{array}{l}\text { Limit of } \\
\text { detection }\end{array}$ & $\begin{array}{l}\text { Reusability } \\
\text { (cycle) }\end{array}$ & Ref \\
\hline $\begin{array}{l}\text { DPV/GCE/ } \\
\text { PBS }\end{array}$ & Dopamine & $\begin{array}{l}\mathrm{CS}+\mathrm{Gr}+\mathrm{T} / \\
\mathrm{CA}\end{array}$ & 1 & $\begin{array}{l}\mathrm{CA} \text { in } \mathrm{KCl} \text { and } \\
\text { ethanol }\end{array}$ & Blood serum & $\begin{array}{l}10^{-9} M-8.10^{-8} M \\
10^{-7} M-10^{-4} M\end{array}$ & $10^{-11} \mathrm{M}$ & I & [77] \\
\hline $\begin{array}{l}\text { DPV/IE1/ } \\
\text { PBS }\end{array}$ & Dopamine & $\begin{array}{l}\mathrm{CS}+\mathrm{T} / \\
\mathrm{CA}\end{array}$ & I & $\mathrm{KCl}$ and ethanol & PBS solution & $\begin{array}{l}0,51 \cdot 10^{-6} \mathrm{M}- \\
1,95 \cdot 10^{-3} \mathrm{M}\end{array}$ & $0,16 \cdot 10^{-6} \mathrm{M}$ & I & [112] \\
\hline $\begin{array}{l}\text { DPV/IE2/ } \\
\text { PBS }\end{array}$ & Dopamine & $\begin{array}{l}\mathrm{CS}+\mathrm{T} / \\
\mathrm{CA}\end{array}$ & I & $\mathrm{KCl}$ and ethanol & PBS solution & $\begin{array}{l}0,12 \cdot 10^{-9} \mathrm{M}- \\
1,52 \cdot 10^{-4} \mathrm{M}\end{array}$ & $0,039 \cdot 10^{-9} \mathrm{M}$ & I & [113] \\
\hline $\begin{array}{l}\text { DPV/GCE/ } \\
\text { Sulfuric acid }\end{array}$ & L-dopa & $\begin{array}{l}\mathrm{CS}+\mathrm{Gr}+\mathrm{T} / \\
\mathrm{CA}\end{array}$ & 1 & $\begin{array}{l}\text { CA in } \mathrm{KCl} \text { and } \\
\text { ethanol }\end{array}$ & Blood serum & $4.10^{-7} \mathrm{M}-10^{-4} \mathrm{M}$ & $0,012 \cdot 10^{-6} \mathrm{M}$ & I & [114] \\
\hline $\begin{array}{l}\text { DPV/Au/ } \\
{\left[\mathrm{Fe}(\mathrm{CN})_{6}\right]^{3-/ 4-}}\end{array}$ & Urea & $\begin{array}{l}C S+Q D s+T / \\
C A\end{array}$ & 1 & $\mathrm{KCl}$ solution & Blood serum & $\begin{array}{l}5.10^{-12} \mathrm{M}-4.10^{-10} \mathrm{M} \\
5.10^{-10} \mathrm{M}-7.10^{-8} \mathrm{M}\end{array}$ & $10^{-12} \mathrm{M}$ & 10 & [104] \\
\hline $\begin{array}{l}\text { DPV/Au/ } \\
\mathrm{Fr}\end{array}$ & Microalbumin & $\begin{array}{l}\text { CS+AM+BAM+ } \\
\text { Gr+Fr+T/ } \\
\text { Drop-coating }\end{array}$ & 1 & $\begin{array}{l}\text { Acetic acid and } \\
\text { Sodium } \\
\text { Dodecylsulfate }\end{array}$ & Urine samples & $\begin{array}{l}1,5 \cdot 10^{-9} \mathrm{M}- \\
1,5 \cdot 10^{-7} \mathrm{M}\end{array}$ & $7,7.10^{-13} \mathrm{M}$ & 9 & [102] \\
\hline $\begin{array}{l}\text { DPV/GCE/ } \\
\text { Acetate } \\
\text { buffer }\end{array}$ & P-nitrophenol & $\begin{array}{l}\text { CS+PTMS+AuN } \\
\mathrm{Ps}+\mathrm{T} / \\
\mathrm{CA}\end{array}$ & 1 & CV in acetate buffer & $\begin{array}{ll}\text { Acetate } & \text { buffer } \\
\text { solutions } & \end{array}$ & $\begin{array}{l}3.10^{-8} \mathrm{M}- \\
5,5.10^{-4} \mathrm{M}\end{array}$ & $5.10^{-9} \mathrm{M}$ & 10 & [78] \\
\hline $\begin{array}{l}\text { DPV/Au/ } \\
\text { PBS }\end{array}$ & $\begin{array}{l}2,4,6- \\
\text { tribromophenol }\end{array}$ & $\begin{array}{l}\mathrm{CS}+\mathrm{T} / \\
\mathrm{CV}\end{array}$ & Sulfuric acid & Sulfuric acid & Clean water & $10^{-7} \mathrm{M}-10^{-3} \mathrm{M}$ & $1,32.10^{-8} \mathrm{M}$ & 5 & [105] \\
\hline $\begin{array}{l}\text { DPV/GCE/ } \\
\text { PBS }\end{array}$ & Bisphenol A & $\begin{array}{l}\mathrm{CS}+\mathrm{AB}+\mathrm{T} / \\
\text { Drop-coating }\end{array}$ & Sulfuric acid & $\begin{array}{l}\text { Methanol and acetic } \\
\text { acid }\end{array}$ & Drinking water & $\begin{array}{l}5.10^{-9} M-2.10^{-7} M \\
5.10^{-7} M-10^{-5} M\end{array}$ & 2. $10^{-9} \mathrm{M}$ & 1 & [101] \\
\hline $\begin{array}{l}\text { DPV/GCE/ } \\
{\left[\mathrm{Ru}\left(\mathrm{NH}_{3}\right)_{6}\right]^{3+1}} \\
{ }_{2+}\end{array}$ & Trichlorphon & $\begin{array}{l}\mathrm{CS}+\mathrm{T} / \\
\mathrm{CA}\end{array}$ & $\begin{array}{l}\text { Glutaraldehyd } \\
\mathrm{e}\end{array}$ & $\mathrm{CA}$ in $\mathrm{KCl}$ & Tea sample & $5.10^{-7} \mathrm{M}-10^{-5} \mathrm{M}$ & $10^{-7} \mathrm{M}$ & 1 & [56] \\
\hline $\begin{array}{l}\text { DPV/Au/ } \\
\text { PBS }\end{array}$ & $\begin{array}{l}\text { Chromium } \\
\text { ions }\end{array}$ & $\begin{array}{l}\mathrm{CS}+\mathrm{Gr}+\mathrm{T} / \\
\mathrm{CA}\end{array}$ & $\begin{array}{l}\text { Glutaraldehyd } \\
\mathrm{e}\end{array}$ & $\begin{array}{l}\text { ethylenediaminetetr } \\
\text { aacetic acid }\end{array}$ & $\begin{array}{l}\text { Tap and river } \\
\text { water }\end{array}$ & $10^{-9} \mathrm{M}-10^{-5} \mathrm{M}$ & $6,4 \cdot 10^{-10} \mathrm{M}$ & 9 & [106] \\
\hline $\begin{array}{l}\text { DPV/GCE/ } \\
\mathrm{HAc}-\mathrm{NaAc} \\
\end{array}$ & copper ions & $\begin{array}{l}\mathrm{CS}+\mathrm{Gr}+\mathrm{T} / \\
\text { Drop-coating }\end{array}$ & $\begin{array}{l}\text { Epichlorohydri } \\
\mathrm{n}\end{array}$ & $\begin{array}{l}\text { ethylenediaminetetr } \\
\text { aacetic acid }\end{array}$ & $\begin{array}{l}\text { tap and river } \\
\text { water }\end{array}$ & $5.10^{-7} \mathrm{M}-10^{-4} \mathrm{M}$ & $0,15.10^{-6} \mathrm{M}$ & 5 & [107] \\
\hline $\begin{array}{l}\text { DPV/GCE/ } \\
\mathrm{HAc}-\mathrm{NaAc}\end{array}$ & cadmium ions & $\begin{array}{l}\text { CS+AuNPs+Gr+ } \\
\text { T/ } \\
\text { CA }\end{array}$ & 1 & $\begin{array}{l}\text { ethylenediaminetetr } \\
\text { aacetic acid }\end{array}$ & $\begin{array}{l}\text { drinking water } \\
\text { and milk } \\
\text { samples }\end{array}$ & $10^{-7} \mathrm{M}-9.10^{-7} \mathrm{M}$ & $1,62.10^{-4} \mathrm{M}$ & 10 & [103] \\
\hline $\begin{array}{l}\text { CV/Au/ } \\
{\left[\mathrm{Fe}(\mathrm{CN})_{6}\right]^{3-/ 4-}}\end{array}$ & Urea & $\begin{array}{l}\mathrm{CS}+\mathrm{T} / \\
\mathrm{CA} \\
\end{array}$ & I & $\mathrm{KCl}$ solution & $\begin{array}{l}\text { Blood serum and } \\
\text { urine }\end{array}$ & $10^{-8} \mathrm{M}-4.10^{-5} \mathrm{M}$ & $5.10^{-9} \mathrm{M}$ & 9 & [108] \\
\hline $\begin{array}{l}\text { CV/Modified } \\
\text { WGE/B-R } \\
\text { Buffer } \\
\end{array}$ & Clenbuterol & $\begin{array}{l}\text { CS+Nafion+T/ } \\
\text { Drop-coating }\end{array}$ & Sulfuric acid & $\begin{array}{l}\text { CA in acetic acid, } \\
\text { phosphoric acid and } \\
\text { boric acid solution }\end{array}$ & Pork liver & $3.10^{-7} \mathrm{M}-5.10^{-5} \mathrm{M}$ & $0,01.10^{-6} \mathrm{M}$ & 5 & [86] \\
\hline
\end{tabular}




\begin{tabular}{|c|c|c|c|c|c|c|c|c|c|}
\hline $\begin{array}{l}\text { CVIABPE/ } \\
\text { PBS }\end{array}$ & BisphenolA & $\begin{array}{l}\text { CS+T/ } \\
\text { Drop-coating }\end{array}$ & Sulfuric acid & Sulfuric acid & Plastic samples & $8.10^{-8} \mathrm{M}-10^{-5} \mathrm{M}$ & $60.10^{-9} \mathrm{M}$ & 7 & [109] \\
\hline $\begin{array}{l}\text { CV/BDD/ } \\
\text { PBS }\end{array}$ & Catechol & $\begin{array}{l}\mathrm{CS}+\mathrm{AuNPs}+\mathrm{MW} \\
\mathrm{CNT}+\mathrm{T} / \\
\text { Drop-coating }\end{array}$ & $\begin{array}{l}\text { Glutaraldehyd } \\
\mathrm{e}\end{array}$ & $\mathrm{KCl}$ solution & wine sample & $7,5.10^{-5} \mathrm{M}-10^{-3} \mathrm{M}$ & $3,7.10^{-5} \mathrm{M}$ & 3 & [25] \\
\hline $\begin{array}{l}\text { CV/BDD/ } \\
\text { PBS }\end{array}$ & Catechol & $\begin{array}{l}\mathrm{CS}+\mathrm{T} / \\
\mathrm{CA}\end{array}$ & I & $\mathrm{KCl}$ solution & wine sample & $\begin{array}{l}5.10^{-5} \mathrm{M}-7,5.10^{-5} \\
\mathrm{M}\end{array}$ & $6,9 \cdot 10^{-7} \mathrm{M}$ & 3 & [24] \\
\hline $\begin{array}{l}\text { SWVIAu/ } \\
{\left[\mathrm{Fe}(\mathrm{CN})_{6}\right]^{3-14-}}\end{array}$ & bisphenol A & $\begin{array}{l}\mathrm{CS}+\mathrm{T} / \\
\mathrm{CA}\end{array}$ & $\begin{array}{l}\text { Glutaraldehyd } \\
\mathrm{e}\end{array}$ & $\begin{array}{l}\text { Ethanol and acetic } \\
\text { acid }\end{array}$ & drinking water & $10^{-3} \mathrm{M}-10^{-21} \mathrm{M}$ & $0,67.10^{-21} \mathrm{M}$ & 10 & [111] \\
\hline $\begin{array}{l}\text { LSV/ABPE/ } \\
\text { PBS }\end{array}$ & Bisphenol A & $\begin{array}{l}\mathrm{CS}+\mathrm{Gr}+\mathrm{T} / \\
\text { Drop-coating }\end{array}$ & Sulfuric acid & $\mathrm{CV}$ in $\mathrm{HCl}$ & $\begin{array}{l}\text { Drinking water } \\
\text { and canned } \\
\text { beverages }\end{array}$ & $\begin{array}{l}8.10^{-9} M-10^{-6} M \\
10^{-6} M-20.10^{-6} M\end{array}$ & $6.10^{-9} \mathrm{M}$ & 10 & [87] \\
\hline $\begin{array}{l}\mathrm{CA} / \mathrm{NiOE} / \\
\mathrm{KOH}\end{array}$ & Glucose & $\begin{array}{l}\mathrm{CS}+\mathrm{T} / \\
\mathrm{CA}\end{array}$ & l & water elution & $\mathrm{KOH}$ solution & $10^{-5} \mathrm{M}-20.10^{-5} \mathrm{M}$ & $2.10^{-6} \mathrm{M}$ & I & [115] \\
\hline $\begin{array}{l}\text { CA/IE2/ } \\
\text { PBS }\end{array}$ & Dopamine & $\begin{array}{l}\mathrm{CS}+\mathrm{T} / \\
\mathrm{CA}\end{array}$ & l & $\mathrm{KCl}$ and ethanol & PBS solution & $\begin{array}{l}0,12 \cdot 10^{-9} \mathrm{M}- \\
152 \cdot 10^{-6} \mathrm{M}\end{array}$ & $0.039 .10^{-9} \mathrm{M}$ & l & [113] \\
\hline $\begin{array}{l}\text { CA/ITO/ } \\
\text { PBS }\end{array}$ & Epinephrine & $\begin{array}{l}\mathrm{CS}+\mathrm{PIL}+\mathrm{MWCN} \\
\mathrm{T}+\mathrm{T} / \\
\mathrm{CA}\end{array}$ & I & $\begin{array}{l}\text { phosphate buffer } \\
\text { solution }\end{array}$ & $\begin{array}{l}\text { phosphate } \\
\text { buffer solution }\end{array}$ & $\begin{array}{l}0,2 \cdot 10^{-6} \mathrm{M}- \\
0,67 \cdot 10^{-3} \mathrm{M}\end{array}$ & $60.10^{-9} \mathrm{M}$ & 9 & [110] \\
\hline $\begin{array}{l}\mathrm{EIS} / \mathrm{Au} / \\
{\left[\mathrm{Fe}(\mathrm{CN})_{6}\right]^{3-14-}}\end{array}$ & Glyphosate & $\begin{array}{l}\mathrm{CS}+\mathrm{T} / \\
\mathrm{CV}\end{array}$ & Sulfuric acid & $\begin{array}{l}\text { Ethanol and acetic } \\
\text { acid }\end{array}$ & River water & $\begin{array}{l}1,83 \cdot 10^{-15} \mathrm{M}- \\
3 \cdot 10^{-10} \mathrm{M}\end{array}$ & $5,9 \cdot 10^{-18} \mathrm{M}$ & 2 & [92] \\
\hline
\end{tabular}

DPV: Pulse Differential Voltammetry

CA: Chronoamperometry

SWV: Square wave voltammetry

CV: Cyclic Voltammetry

LSV: Linear Sweep Voltammetry

EIS: Electrochemical Impedance Spectroscopy

Au: Gold electrode

GCE: Glass Carbon Electrode

IE1: Integrated electrode $\mathrm{CuCo}_{2} \mathrm{O}_{4} @$ carbon nanocoposites/Three-dimensional kenaf stem-derived marcoporous carbon

IE2: Integrated electrode ZnO@carbon nanocoposites/Three-dimensional kenaf stem-derived marcoporous carbon

Modified WGE: electrode Nano-silver/Quercetin/Working graphite

ABPE: Acetylene Black Paste Electrode

BDD: Bored-Doped Diamond electrode

NiOE: Nickel Oxide Electrode

PBS: Phosphate Buffer Solution

B-R Buffer: Britton-Robinson Buffer

HAc-NaAc: Acetic acid-Sodium Acetate

T: Template

Gr: Graphene

QDs: Quantum Dots

AM: Acrylamide

BAM: N,N'-methylenebisacrylamide 
Fr: Ferrocene

PTMS: Phenyltrimethoxysilane

AuNPs: Gold Nanoparticles

AB: Acetylene Black

MWCNT: Multiwalled carbon nanotubes 


\section{Conclusion and perspectives}

Molecular imprinted polymers are a very good choice which has been applied in several fields. Their relevant properties make them very attractive for replacing biological entities in various applications. Chitosan has been considered as an interesting biopolymer for the development of MIPs because of its excellent properties.

Chitosan-MIPs have been successfully integrated into the transducer area for the development of electrochemical sensors. The physicochemical characteristics of chitosan have been exploited to manufacture membranes, thin films and three-dimensional structures by various methods. Electrodeposition is a simple, easy, fast and low-cost technique. It allows the deposition of very porous chitosan films in a controlled manner.

The imprinting of small molecules like pesticides and pharmaceuticals is well established in the synthesis of MIPs and considered routine; however the imprinting of much larger structures remains a challenge. The behavior of chitosan is interrupted by several parameters which undoubtedly affects the sensitivity of the sensors developed. The properties of chitosan should allow the introduction of chemical modifications which can collectively lead to major performance improvements. In the future, multi-imprinting of several templates could be performed on the CS, which can open the door to a fascinating range of fundamental experiments.

Acknowledgements: The authors acknowledge the financial support of the EU H2020 research and innovation program entitled KardiaTool grant \#768686 and from CAMPUS FRANCE program under grant agreement PROFAS B+ and PHC MAGHREB \#39382RE.

\section{Declaration of interests:}

The authors declare that they have no known competing financial interests or personal relationships that could have appeared to influence the work reported in this paper.

\section{References:}

[1] M.-P.N. Bui, J. Brockgreitens, S. Ahmed, A. Abbas, Dual detection of nitrate and mercury in water using disposable electrochemical sensors, Biosensors and Bioelectronics. 85 (2016) 280-286. https://doi.org/10.1016/j.bios.2016.05.017.

[2] U. Guth, W. Vonau, J. Zosel, Recent developments in electrochemical sensor application and technology-a review, Measurement Science and Technology. 20 (2009) 042002. https://doi.org/10.1088/0957-0233/20/4/042002.

[3] P. Yáñez-Sedeño, S. Campuzano, J.M. Pingarrón, Electrochemical sensors based on magnetic molecularly imprinted polymers: A review, Analytica Chimica Acta. 960 (2017) 1-17. https://doi.org/10.1016/j.aca.2017.01.003.

[4] F.W. Scheller, X. Zhang, A. Yarman, U. Wollenberger, R.E. Gyurcsányi, Molecularly imprinted polymer-based electrochemical sensors for biopolymers, Current Opinion in Electrochemistry. 14 (2019) 53-59. https://doi.org/10.1016/j.coelec.2018.12.005.

[5] G. Wulff, The use of polymers with enzyme-analogous structures for the resolution of racemates, Angrew. Chem. Internat. Edit. 11 (1972) 341

[6] J. O’Mahony, B.C.G. Karlsson, B. Mizaikoff, I.A. Nicholls, Correlated theoretical, spectroscopic and X-ray crystallographic studies of a non-covalent molecularly imprinted polymerisation system, The Analyst. 132 (2007) 1161. https://doi.org/10.1039/b706258c.

[7] K. Singh, S. Balasubramanian, B.E. Amitha Rani, Computational and Experimental Studies of Molecularly Imprinted Polymers for Organochlorine Pesticides Heptachlor and DDT, Current Analytical Chemistry. 8 (2012) 562-568. https://doi.org/10.2174/157341112803216807.

[8] G.Z. Kyzas, N.K. Lazaridis, D.N. Bikiaris, Optimization of chitosan and $\beta$-cyclodextrin molecularly imprinted polymer synthesis for dye adsorption, Carbohydrate Polymers. 91 (2013) 198-208. https://doi.org/10.1016/j.carbpol.2012.08.016.

[9] H. Yu, Z. Chen, Y. Fu, L. Kang, M. Wang, X. Du, Synthesis and optimization of molecularly imprinted polymers for quercetin, Polymer International. 61 (2012) 1002-1009. https://doi.org/10.1002/pi.4172.

[10] F. Qiao, H. Sun, H. Yan, K.H. Row, Molecularly Imprinted Polymers for Solid Phase Extraction, Chromatographia. 64 (2006) 625-634. https://doi.org/10.1365/s10337-006-0097-2.

[11] K. Haupt, K. Mosbach, Molecularly Imprinted Polymers and Their Use in Biomimetic Sensors, Chemical Reviews. 100 (2000) 2495-2504. https://doi.org/10.1021/cr990099w.

[12] J. Orozco, A. Cortés, G. Cheng, S. Sattayasamitsathit, W. Gao, X. Feng, Y. Shen, J. Wang, Molecularly Imprinted PolymerBased Catalytic Micromotors for Selective Protein Transport, Journal of the American Chemical Society. 135 (2013) 53365339. https://doi.org/10.1021/ja4018545.

[13] A. Nezhadali, M. Mojarrab, Computational study and multivariate optimization of hydrochlorothiazide analysis using molecularly imprinted polymer electrochemical sensor based on carbon nanotube/polypyrrole film, Sensors and Actuators B: Chemical. 190 (2014) 829-837. https://doi.org/10.1016/j.snb.2013.08.086.

[14] E. Turiel, A. Martín-Esteban, Molecularly imprinted polymers for sample preparation: A review, Analytica Chimica Acta. 668 (2010) 87-99. https://doi.org/10.1016/j.aca.2010.04.019.

[15] P.K. Dutta, J. Dutta, V. Tripathi, Chitin and chitosan: Chemistry, properties and applications, (2004).

[16] R. Jayakumar, M. Prabaharan, R.L. Reis, J.F. Mano, Graft copolymerized chitosan-present status and applications, Carbohydrate Polymers. 62 (2005) 142-158. https://doi.org/10.1016/j.carbpol.2005.07.017.

[17] A. Grenha, C.I. Grainger, L.A. Dailey, B. Seijo, G.P. Martin, C. Remuñán-López, B. Forbes, Chitosan nanoparticles are compatible with respiratory epithelial cells in vitro, European Journal of Pharmaceutical Sciences. 31 (2007) 73-84. https://doi.org/10.1016/j.ejps.2007.02.008.

[18] M.-C. Li, J.K. Lee, U.R. Cho, Synthesis, characterization, and enzymatic degradation of starch-grafted poly(methyl methacrylate) copolymer films, Journal of Applied Polymer Science. 125 (2012) 405-414. https://doi.org/10.1002/app.35620.

[19] Y. Wang, E. Wang, Z. Wu, H. Li, Z. Zhu, X. Zhu, Y. Dong, Synthesis of chitosan molecularly imprinted polymers for solidphase extraction of methandrostenolone, Carbohydrate Polymers. $101 \quad$ (2014) 517-523. https://doi.org/10.1016/j.carbpol.2013.09.078. 
[20] X. Wang, M. Wu, W. Tang, Y. Zhu, L. Wang, Q. Wang, P. He, Y. Fang, Simultaneous electrochemical determination of ascorbic acid, dopamine and uric acid using a palladium nanoparticle/graphene/chitosan modified electrode, Journal of Electroanalytical Chemistry. 695 (2013) 10-16. https://doi.org/10.1016/j.jelechem.2013.02.021.

[21] T.I. Nasution, I. Nainggolan, S.D. Hutagalung, K.R. Ahmad, Z.A. Ahmad, The sensing mechanism and detection of low concentration acetone using chitosan-based sensors, Sensors and Actuators B: Chemical. 177 (2013) 522-528. https://doi.org/10.1016/j.snb.2012.11.063.

[22] P.M. Claesson, B.W. Ninham, pH-dependent interactions between adsorbed chitosan layers, Langmuir. 8 (1992) $1406-1412$. https://doi.org/10.1021/la00041a027.

[23] V. Tangpasuthadol, N. Pongchaisirikul, V.P. Hoven, Surface modification of chitosan films., Carbohydrate Research. 338 (2003) 937-942. https://doi.org/10.1016/s0008-6215(03)00038-7.

[24] C. Salvo-Comino, I. Rassas, S. Minot, F. Bessueille, M.L. Rodriguez-Mendez, A. Errachid, N. Jaffrezic-Renault, Voltammetric sensor based on electrodeposited molecularly imprinted chitosan film on BDD electrodes for catechol detection in buffer and in wine samples, Materials Science and Engineering: C. 110 (2020) 110667. https://doi.org/10.1016/j.msec.2020.110667.

[25] C. Salvo-Comino, I. Rassas, S. Minot, F. Bessueille, M. Arab, V. Chevallier, M.L. Rodriguez-Mendez, A. Errachid, N. JaffrezicRenault, Voltammetric Sensor Based on Molecularly Imprinted Chitosan-Carbon Nanotubes Decorated with Gold Nanoparticles Nanocomposite Deposited on Boron-Doped Diamond Electrodes for Catechol Detection, Materials. 13 (2020) 688. https://doi.org/10.3390/ma13030688.

[26] H. Yi, L.-Q. Wu, W.E. Bentley, R. Ghodssi, G.W. Rubloff, J.N. Culver, G.F. Payne, Biofabrication with Chitosan, Biomacromolecules. 6 (2005) 2881-2894. https://doi.org/10.1021/bm050410l.

[27] I. Aranaz, M. Mengibar, R. Harris, I. Panos, B. Miralles, N. Acosta, G. Galed, A. Heras, Functional Characterization of Chitin and Chitosan, Current Chemical Biology. 3 (2009) 203-230. https://doi.org/10.2174/187231309788166415.

[28] I. Younes, M. Rinaudo, Chitin and Chitosan Preparation from Marine Sources. Structure, Properties and Applications, Marine Drugs. 13 (2015) 1133-1174. https://doi.org/10.3390/md13031133.

[29] H. El Knidri, R. Belaabed, A. Addaou, A. Laajeb, A. Lahsini, Extraction, chemical modification and characterization of chitin and chitosan, International Journal of Biological Macromolecules. 120 (2018) 1181-1189. https://doi.org/10.1016/j.ijbiomac.2018.08.139.

[30] A. Domard, M. Domard, Chitosan: structure-properties relationship and biomedical applications, Polymeric Biomaterials. 2 (2001) 187-212.

[31] P. Sorlier, C. Rochas, I. Morfin, C. Viton, A. Domard, Light Scattering Studies of the Solution Properties of Chitosans of Varying Degrees of Acetylation, Biomacromolecules. 4 (2003) 1034-1040. https://doi.org/10.1021/bm034054n.

[32] L. Raymond, F.G. Morin, R.H. Marchessault, Degree of deacetylation of chitosan using conductometric titration and solidstate NMR, Carbohydrate Research. 246 (1993) 331-336. https://doi.org/10.1016/0008-6215(93)84044-7.

[33] Z.M. dos Santos, A.L.P.F. Caroni, M.R. Pereira, D.R. da Silva, J.L.C. Fonseca, Determination of deacetylation degree of chitosan: a comparison between conductometric titration and CHN elemental analysis, Carbohydrate Research. 344 (2009) 2591-2595. https://doi.org/10.1016/j.carres.2009.08.030.

[34] X. Jiang, L. Chen, W. Zhong, A new linear potentiometric titration method for the determination of deacetylation degree of chitosan, Carbohydrate Polymers. 54 (2003) 457-463. https://doi.org/10.1016/j.carbpol.2003.05.004.

[35] M.R. Kasaai, Determination of the degree of N-acetylation for chitin and chitosan by various NMR spectroscopy techniques: A review, Carbohydrate Polymers. 79 (2010) 801-810. https://doi.org/10.1016/j.carbpol.2009.10.051.

[36] V. Zargar, M. Asghari, A. Dashti, A Review on Chitin and Chitosan Polymers: Structure, Chemistry, Solubility, Derivatives, and Applications, ChemBioEng Reviews. 2 (2015) 204-226. https://doi.org/10.1002/cben.201400025.

[37] I. Tsigos, A. Martinou, D. Kafetzopoulos, V. Bouriotis, Chitin deacetylases: new, versatile tools in biotechnology, Trends in Biotechnology. 18 (2000) 305-312. https://doi.org/10.1016/S0167-7799(00)01462-1.

[38] S. Kim, N. Rajapakse, Enzymatic production and biological activities of chitosan oligosaccharides (COS): A review, Carbohydrate Polymers. 62 (2005) 357-368. https://doi.org/10.1016/j.carbpol.2005.08.012.

[39] Y. Zhao, R.-D. Park, R.A.A. Muzzarelli, Chitin Deacetylases: Properties and Applications, Marine Drugs. 8 (2010) 24-46. https://doi.org/10.3390/md8010024.

[40] S. Naqvi, S. Cord-Landwehr, R. Singh, F. Bernard, S. Kolkenbrock, N.E. El Gueddari, B.M. Moerschbacher, A Recombinant Fungal Chitin Deacetylase Produces Fully Defined Chitosan Oligomers with Novel Patterns of Acetylation, Appl. Environ. Microbiol. 82 (2016) 6645-6655. https://doi.org/10.1128/AEM.01961-16.

[41] H.K. No, S.P. Meyers, W. Prinyawiwatkul, Z. Xu, Applications of Chitosan for Improvement of Quality and Shelf Life of Foods: A Review, J Food Science. 72 (2007) R87-R100. https://doi.org/10.1111/j.1750-3841.2007.00383.x.

[42] R. Cheung, T. Ng, J. Wong, W. Chan, Chitosan: An Update on Potential Biomedical and Pharmaceutical Applications, Marine Drugs. 13 (2015) 5156-5186. https://doi.org/10.3390/md13085156.

[43] I. Hamed, F. Özogul, J.M. Regenstein, Industrial applications of crustacean by-products (chitin, chitosan, and chitooligosaccharides): A review, Trends in Food Science \& Technology. 48 (2016) 40-50. https://doi.org/10.1016/j.tifs.2015.11.007.

[44] A. Bhatnagar, M. Sillanpää, Applications of chitin- and chitosan-derivatives for the detoxification of water and wastewater A short review, Advances in Colloid and Interface Science. 152 (2009) 26-38. https://doi.org/10.1016/j.cis.2009.09.003.

[45] R.A.A. Muzzarelli, Potential of chitin/chitosan-bearing materials for uranium recovery: An interdisciplinary review, Carbohydrate Polymers. 84 (2011) 54-63. https://doi.org/10.1016/j.carbpol.2010.12.025.

[46] M. Hasegawa, A. Isogai, F. Onabe, Preparation of low-molecular-weight chitosan using phosphoric acid, Carbohydrate Polymers. 20 (1993) 279-283. https://doi.org/10.1016/0144-8617(93)90100-I.

[47] W.A. Bough, W.L. Salter, A.C.M. Wu, B.E. Perkins, Influence of manufacturing variables on the characteristics and effectiveness of chitosan products. I. Chemical composition, viscosity, and molecular-weight distribution of chitosan products, Biotechnol. Bioeng. 20 (1978) 1931-1943. https://doi.org/10.1002/bit.260201208.

[48] J. Pa, T.L. Yu, Light scattering study of chitosan in acetic acid aqueous solutions, Macromolecular Chemistry and Physics. 202 (2001) 985-991.

[49] I. Aranaz, R. Harris, A. Heras, Chitosan amphiphilic derivatives. Chemistry and applications, Current Organic Chemistry. 14 (2010) 308-330.

[50] M. Dash, F. Chiellini, R.M. Ottenbrite, E. Chiellini, Chitosan-A versatile semi-synthetic polymer in biomedical applications, Progress in Polymer Science. 36 (2011) 981-1014. https://doi.org/10.1016/j.progpolymsci.2011.02.001. 
[51] T. Ahmed, B. Aljaeid, Preparation, characterization, and potential application of chitosan, chitosan derivatives, and chitosan metal nanoparticles in pharmaceutical drug delivery, Drug Design, Development and Therapy. (2016) 483. https://doi.org/10.2147/DDDT.S99651.

[52] M. Rinaudo, Chitin and chitosan: Properties and applications, Progress in Polymer Science. 31 (2006) 603-632. https://doi.org/10.1016/j.progpolymsci.2006.06.001.

[53] C. Tual, E. Espuche, M. Escoubes, A. Domard, Transport properties of chitosan membranes: influence of crosslinking, Journal of Polymer Science Part B: Polymer Physics. 38 (2000) 1521-1529.

[54] B. Sellergren, L. Andersson, Molecular recognition in macroporous polymers prepared by a substrate analog imprinting strategy, The Journal of Organic Chemistry. 55 (1990) 3381-3383.

[55] J. Zhang, W. Xia, P. Liu, Q. Cheng, T. Tahi, W. Gu, B. Li, Chitosan Modification and Pharmaceutical/Biomedical Applications, Marine Drugs. 8 (2010) 1962-1987. https://doi.org/10.3390/md8071962.

[56] J. Chen, H. Lian, X. Sun, B. Liu, Development of a chitosan molecularly imprinted electrochemical sensor for trichlorphon determination, International Journal of Environmental Analytical Chemistry. 92 (2012) 1046-1058. https://doi.org/10.1080/03067319.2010.496054.

[57] P. Sorlier, A. Denuzière, C. Viton, A. Domard, Relation between the degree of acetylation and the electrostatic properties of chitin and chitosan, Biomacromolecules. 2 (2001) 765-772.

[58] C. Schatz, C. Pichot, T. Delair, C. Viton, A. Domard, Static Light Scattering Studies on Chitosan Solutions: From Macromolecular Chains to Colloidal Dispersions, Langmuir. 19 (2003) 9896-9903. https://doi.org/10.1021/la034410n.

[59] A.S. Carreira, F.A.M.M. Gonçalves, P.V. Mendonça, M.H. Gil, J.F.J. Coelho, Temperature and pH responsive polymers based on chitosan: Applications and new graft copolymerization strategies based on living radical polymerization, Carbohydrate Polymers. 80 (2010) 618-630. https://doi.org/10.1016/j.carbpol.2009.12.047.

[60] T. Wanjun, W. Cunxin, C. Donghua, Kinetic studies on the pyrolysis of chitin and chitosan, Polymer Degradation and Stability. 87 (2005) 389-394. https://doi.org/10.1016/j.polymdegradstab.2004.08.006.

[61] G.C. Ritthidej, T. Phaechamud, T. Koizumi, Moist heat treatment on physicochemical change of chitosan salt films, International Journal of Pharmaceutics. 232 (2002) 11-22. https://doi.org/10.1016/S0378-5173(01)00894-8.

[62] A. Toffey, W.G. Glasser, Chitin derivatives III Formation of amidized homologs of chitosan, Cellulose. 8 (2001) $35-47$.

[63] L. Lim, E. Khor, C. Ling, Effects of dry heat and saturated steam on the physical properties of chitosan, Journal of Biomedical Materials Research: An Official Journal of The Society for Biomaterials, The Japanese Society for Biomaterials, and The Australian Society for Biomaterials. 48 (1999) 111-116.

[64] C.A. Murray, J.R. Dutcher, Effect of Changes in Relative Humidity and Temperature on Ultrathin Chitosan Films, Biomacromolecules. 7 (2006) 3460-3465. https://doi.org/10.1021/bm060416q.

[65] J. Wang, L. Wang, H. Yu, Zain-ul-Abdin, Y. Chen, Q. Chen, W. Zhou, H. Zhang, X. Chen, Recent progress on synthesis, property and application of modified chitosan: An overview, International Journal of Biological Macromolecules. 88 (2016) 333-344. https://doi.org/10.1016/j.ijbiomac.2016.04.002.

[66] L. Xu, Y.-A. Huang, Q.-J. Zhu, C. Ye, Chitosan in Molecularly-Imprinted Polymers: Current and Future Prospects, International Journal of Molecular Sciences. 16 (2015) 18328-18347. https://doi.org/10.3390/ijms160818328.

[67] E. Szymańska, K. Winnicka, Stability of Chitosan-A Challenge for Pharmaceutical and Biomedical Applications, Marine Drugs. 13 (2015) 1819-1846. https://doi.org/10.3390/md13041819.

[68] K. Gupta, F. Jabrail, Effects of degree of deacetylation and cross-linking on physical characteristics, swelling and release behavior of chitosan microspheres, Carbohydrate Polymers. 66 (2006) 43-54. https://doi.org/10.1016/j.carbpol.2006.02.019.

[69] Y. Yuan, B.M. Chesnutt, G. Utturkar, W.O. Haggard, Y. Yang, J.L. Ong, J.D. Bumgardner, The effect of cross-linking of chitosan microspheres with genipin on protein release, Carbohydrate Polymers. 68 (2007) 561-567. https://doi.org/10.1016/j.carbpol.2006.10.023.

[70] M.S. Chiou, H.Y. Li, Adsorption behavior of reactive dye in aqueous solution on chemical cross-linked chitosan beads, Chemosphere. 50 (2003) 1095-1105. https://doi.org/10.1016/S0045-6535(02)00636-7.

[71] Y.-L. Liu, Y.-H. Su, J.-Y. Lai, In situ crosslinking of chitosan and formation of chitosan-silica hybrid membranes with using Yglycidoxypropyltrimethoxysilane as a crosslinking agent, Polymer. $45 \quad(2004)$ 6831-6837. https://doi.org/10.1016/j.polymer.2004.08.006.

[72] J.D. Schiffman, C.L. Schauer, Cross-Linking Chitosan Nanofibers, Biomacromolecules. 8 (2007) 594-601. https://doi.org/10.1021/bm060804s.

[73] F.S. Pereira, D.L. da Silva Agostini, A.E. Job, E.R.P. González, Thermal studies of chitin-chitosan derivatives, J Therm Anal Calorim. 114 (2013) 321-327. https://doi.org/10.1007/s10973-012-2835-z.

[74] A.O. Martins, E.L. da Silva, E. Carasek, N.S. Gonçalves, M.C.M. Laranjeira, V.T. de Fávere, Chelating resin from functionalization of chitosan with complexing agent 8-hydroxyquinoline: application for metal ions on line preconcentration system, Analytica Chimica Acta. 521 (2004) 157-162. https://doi.org/10.1016/j.aca.2004.06.033.

[75] P.R. Solanki, A. Kaushik, A.A. Ansari, A. Tiwari, B.D. Malhotra, Multi-walled carbon nanotubes/sol-gel-derived silica/chitosan nanobiocomposite for total cholesterol sensor, Sensors and Actuators B: Chemical. 137 (2009) $727-735$. https://doi.org/10.1016/j.snb.2008.12.044.

[76] T.W. Chung, J. Yang, T. Akaike, K.Y. Cho, J.W. Nah, S.I. Kim, C.S. Cho, Preparation of alginate/galactosylated chitosan scaffold for hepatocyte attachment, Biomaterials. 23 (2002) 2827-2834. https://doi.org/10.1016/S0142-9612(01)00399-4.

[77] B. Liu, H.T. Lian, J.F. Yin, X.Y. Sun, Dopamine molecularly imprinted electrochemical sensor based on graphene-chitosan composite, Electrochimica Acta. 75 (2012) 108-114. https://doi.org/10.1016/j.electacta.2012.04.081.

[78] S. Li, D. Du, J. Huang, H. Tu, Y. Yang, A. Zhang, One-step electrodeposition of a molecularly imprinting chitosan/phenyltrimethoxysilane/AuNPs hybrid film and its application in the selective determination of $p$-nitrophenol, Analyst. 138 (2013) 2761. https://doi.org/10.1039/c3an36497f.

[79] C. Caner, P.J. Vergano, J.L. Wiles, Chitosan Film Mechanical and Permeation Properties as Affected by Acid, Plasticizer, and Storage, Journal of Food Science. 63 (2006) 1049-1053. https://doi.org/10.1111/j.1365-2621.1998.tb15852.x.

[80] G.A.F. Roberts, J.G. Domszy, Determination of the viscometric constants for chitosan, International Journal of Biological Macromolecules. 4 (1982) 374-377. https://doi.org/10.1016/0141-8130(82)90074-5.

[81] M. Lopez-Nogueroles, S. Lordel-Madeleine, A. Chisvert, A. Salvador, V. Pichon, Development of a selective solid phase extraction method for nitro musk compounds in environmental waters using a molecularly imprinted sorbent, Talanta. 110 (2013) 128-134. https://doi.org/10.1016/j.talanta.2013.02.023. 
[82] R. Lorenzo, A. Carro, C. Alvarez-Lorenzo, A. Concheiro, To Remove or Not to Remove? The Challenge of Extracting the Template to Make the Cavities Available in Molecularly Imprinted Polymers (MIPs), International Journal of Molecular Sciences. 12 (2011) 4327-4347. https://doi.org/10.3390/ijms12074327.

[83] E. Turiel, A. Martín-Esteban, P. Fernández, C. Pérez-Conde, C. Cámara, Molecular Recognition in a Propazine-imprinted Polymer and Its Application to the Determination of Triazines in Environmental Samples, Analytical Chemistry. 73 (2001) 5133-5141. https://doi.org/10.1021/ac0105538.

[84] H. Yan, K. Row, Characteristic and Synthetic Approach of Molecularly Imprinted Polymer, International Journal of Molecular Sciences. 7 (2006) 155-178. https://doi.org/10.3390/i7050155.

[85] J. Svenson, I.A. Nicholls, On the thermal and chemical stability of molecularly imprinted polymers, Analytica Chimica Acta. 435 (2001) 19-24. https://doi.org/10.1016/S0003-2670(00)01396-9.

[86] C. Zhao, G.-P. Jin, L.-L. Chen, Y. Li, B. Yu, Preparation of molecular imprinted film based on chitosan/nafion/nano-silver/poly quercetin for clenbuterol sensing, Food Chemistry. 129 (2011) 595-600. https://doi.org/10.1016/j.foodchem.2011.04.072.

[87] P. Deng, Z. Xu, Y. Kuang, Electrochemical determination of bisphenol A in plastic bottled drinking water and canned beverages using a molecularly imprinted chitosan-graphene composite film modified electrode, Food Chemistry. 157 (2014) 490-497. https://doi.org/10.1016/j.foodchem.2014.02.074.

[88] H. Li, C. Xie, X. Fu, Electrochemiluminescence sensor for sulfonylurea herbicide with molecular imprinting core-shell nanoparticles/chitosan composite film modified glassy carbon electrode, Sensors and Actuators B: Chemical. 181 (2013) 858-866. https://doi.org/10.1016/j.snb.2013.02.094.

[89] X. Pang, I. Zhitomirsky, Electrodeposition of composite hydroxyapatite-chitosan films, Materials Chemistry and Physics. 94 (2005) 245-251. https://doi.org/10.1016/j.matchemphys.2005.04.040.

[90] L.-Q. Wu, H. Yi, S. Li, G.W. Rubloff, W.E. Bentley, R. Ghodssi, G.F. Payne, Spatially Selective Deposition of a Reactive Polysaccharide Layer onto a Patterned Template, Langmuir. 19 (2003) 519-524. https://doi.org/10.1021/la026518t.

[91] R. Fernandes, L.-Q. Wu, T. Chen, H. Yi, G.W. Rubloff, R. Ghodssi, W.E. Bentley, G.F. Payne, Electrochemically Induced Deposition of a Polysaccharide Hydrogel onto a Patterned Surface, Langmuir. 19 (2003) 4058-4062. https://doi.org/10.1021/la027052h.

[92] F. Zouaoui, S. Bourouina-Bacha, M. Bourouina, I. Abroa-Nemeir, H. Ben Halima, J. Gallardo-Gonzalez, N. El Alami El Hassani, A. Alcacer, J. Bausells, N. Jaffrezic-Renault, N. Zine, A. Errachid, Electrochemical impedance spectroscopy determination of glyphosate using a molecularly imprinted chitosan, Sensors and Actuators B: Chemical. 309 (2020) 127753. https://doi.org/10.1016/j.snb.2020.127753.

[93] S. Boudjaoui, Développement et optimisation de capteurs de gaz à base de silicium: analyse des composés organiques volatils contenus dans l'air expiré par les patients atteints d'insuffisance cardiaque, (2018).

[94] C. Algieri, E. Drioli, L. Guzzo, L. Donato, Bio-Mimetic Sensors Based on Molecularly Imprinted Membranes, Sensors. 14 (2014) 13863-13912. https://doi.org/10.3390/s140813863.

[95] A. Ellwanger, L. Karlsson, P.K. Owens, C. Berggren, C. Crecenzi, K. Ensing, S. Bayoudh, P. Cormack, D. Sherrington, B. Sellergren, Evaluation of methods aimed at complete removal of template from molecularly imprinted polymers, The Analyst. 126 (2001) 784-792. https://doi.org/10.1039/b009693h.

[96] T.-Y. Guo, Y.-Q. Xia, J. Wang, M.-D. Song, B.-H. Zhang, Chitosan beads as molecularly imprinted polymer matrix for selective separation of proteins, Biomaterials. 26 (2005) 5737-5745. https://doi.org/10.1016/j.biomaterials.2005.02.017.

[97] D. Teng, J. Hou, X. Zhang, X. Wang, Z. Wang, C. Li, Glucosamine-carrying temperature- and pH-sensitive microgels: Preparation, characterization, and in vitro drug release studies, Journal of Colloid and Interface Science. 322 (2008) 333341. https://doi.org/10.1016/j.jcis.2008.03.014.

[98] H.L. Zhao, T.Y. Guo, Y.Q. Xia, M.D. Song, Hemoglobin-imprinted polymer gel prepared using modified glucosamine as functional monomer, Chinese Chemical Letters. 19 (2008) 233-236. https://doi.org/10.1016/j.cclet.2007.10.045.

[99] G. Liu, T. Li, X. Yang, Y. She, M. Wang, J. Wang, M. Zhang, S. Wang, F. Jin, M. Jin, H. Shao, Z. Jiang, H. Yu, Competitive fluorescence assay for specific recognition of atrazine by magnetic molecularly imprinted polymer based on Fe 304 chitosan, Carbohydrate Polymers. 137 (2016) 75-81. https://doi.org/10.1016/j.carbpol.2015.10.062.

[100] W. Guo, F. Pi, H. Zhang, J. Sun, Y. Zhang, X. Sun, A novel molecularly imprinted electrochemical sensor modified with carbon dots, chitosan, gold nanoparticles for the determination of patulin, Biosensors and Bioelectronics. 98 (2017) $299-304$. https://doi.org/10.1016/j.bios.2017.06.036.

[101] Y. Tan, J. Jin, S. Zhang, Z. Shi, J. Wang, J. Zhang, W. Pu, C. Yang, Electrochemical Determination of Bisphenol A Using a Molecularly Imprinted Chitosan-acetylene Black Composite Film Modified Glassy Carbon Electrode, Electroanalysis. 28 (2016) 189-196. https://doi.org/10.1002/elan.201500533.

[102] A. Fatoni, A. Numnuam, P. Kanatharana, W. Limbut, P. Thavarungkul, A novel molecularly imprinted chitosan-acrylamide, graphene, ferrocene composite cryogel biosensor used to detect microalbumin, Analyst. 139 (2014) 6160-6167. https://doi.org/10.1039/C4AN01000K.

[103] S. Wu, K. Li, X. Dai, Z. Zhang, F. Ding, S. Li, An ultrasensitive electrochemical platform based on imprinted chitosan/gold nanoparticles/graphene nanocomposite for sensing cadmium (II) ions, Microchemical Journal. 155 (2020) 104710. https://doi.org/10.1016/j.microc.2020.104710.

[104] H.-T. Lian, B. Liu, Y.-P. Chen, X.-Y. Sun, A urea electrochemical sensor based on molecularly imprinted chitosan film doping with CdS quantum dots, Analytical Biochemistry. 426 (2012) 40-46. https://doi.org/10.1016/j.ab.2012.03.024.

[105] L. Huang, Y. Lu, Z. Wu, M. Li, S. Xiang, X. Ma, Z. Zhang, A Facile Approach to Preparing Molecularly Imprinted Chitosan for Detecting 2,4,6-Tribromophenol with a Widely Linear Range, Environments. $4 \quad$ (2017) 30. https://doi.org/10.3390/environments4020030.

[106] S. Wu, X. Dai, T. Cheng, S. Li, Highly sensitive and selective ion-imprinted polymers based on one-step electrodeposition of chitosan-graphene nanocomposites for the determination of $\operatorname{Cr}(\mathrm{VI})$, Carbohydrate Polymers. 195 (2018) $199-206$. https://doi.org/10.1016/j.carbpol.2018.04.077.

[107] P. Wei, Z. Zhu, R. Song, Z. Li, C. Chen, An ion-imprinted sensor based on chitosan-graphene oxide composite polymer modified glassy carbon electrode for environmental sensing application, Electrochimica Acta. 317 (2019) 93-101. https://doi.org/10.1016/j.electacta.2019.05.136.

[108] Y.-P. Chen, B. Liu, H.-T. Lian, X.-Y. Sun, Preparation and Application of Urea Electrochemical Sensor Based on Chitosan Molecularly Imprinted Films, Electroanalysis. 23 (2011) 1454-1461. https://doi.org/10.1002/elan.201000693.

[109] P. Deng, Z. Xu, J. Li, Y. Kuang, Acetylene black paste electrode modified with a molecularly imprinted chitosan film for the detection of bisphenol A, Microchim Acta. 180 (2013) 861-869. https://doi.org/10.1007/s00604-013-1001-z. 
[110] Y. Wu, X. Feng, S. Zhou, H. Shi, H. Wu, S. Zhao, W. Song, Sensing epinephrine with an ITO electrode modified with an imprinted chitosan film containing multi-walled carbon nanotubes and a polymerized ionic liquid, Microchimica Acta. 180 (2013) 1325-1332. https://doi.org/10.1007/s00604-013-1063-y.

[111] H. Chakroun Galai, P. Namour, A. Bonhomme, F. Bessueille, S. Besbes Hentati, N. Jaffrezic-Renault, Elaboration of an Imprinted Polymer Film Based on Chitosan Electrodeposition for the Voltammetric Detection of BPA, Journal of The Electrochemical Society. 167 (2020) 027507. https://doi.org/10.1149/1945-7111/ab6283.

[112] L. Wang, H. Yang, L. Xu, C. Peng, Y. Song, A novel popamine-imprinted chitosan/CuCo2O4@carbon/three-dimensional macroporous carbon integrated electrode, Journal of Alloys and Compounds. 817 (2020) 152771. https://doi.org/10.1016/j.jallcom.2019.152771.

[113] Y. Song, J. Han, L. Xu, L. Miao, C. Peng, L. Wang, A dopamine-imprinted chitosan Film/Porous ZnO NPs@carbon Nanospheres/Macroporous carbon for electrochemical sensing dopamine, Sensors and Actuators B: Chemical. 298 (2019) 126949. https://doi.org/10.1016/j.snb.2019.126949.

[114] L. Lin, H.-T. Lian, X.-Y. Sun, Y.-M. Yu, B. Liu, An L-dopa electrochemical sensor based on a graphene doped molecularly imprinted chitosan film, Analytical Methods. 7 (2015) 1387-1394.

[115] H.X. Li, W. Yao, Q. Wu, W.S. Xia, Glucose Molecularly Imprinted Electrochemical Sensor Based on Chitosan and Nickel $\begin{array}{lllll}\text { Oxide Electrode, } \quad \text { Advanced } \quad \text { Materials } & \text { Research. } & 1052 & (2014) & 215-219 .\end{array}$ https://doi.org/10.4028/www.scientific.net/AMR.1052.215. 